\title{
New cave-dwelling amphipods (Lysianassidae, Hadziidae) from the Dominican Republic (Hispaniola)
}

\author{
Damià Jaume ${ }^{1}$ \& H. P. Wagner ${ }^{2}$ \\ ${ }^{1}$ Instituto Mediterráneo de Estudios Avanzados (CSIC-UIB), Ctra. Valldemossa, km 7'5, 07071 Palma de \\ Mallorca, Spain; ${ }^{2}$ Platanenrode 6, NL-2317 BT Leiden, The Netherlands
}

Keywords: Crustacea, Amphipoda, Ottenwalderia gen. nov., Bahadzia, anchialine caves, stygobionts, taxonomy, biogeography

\begin{abstract}
Two new stygobiont amphipods are described from anchialine caves located in the Jaragua region (Pedernales Prov., Dominican Republic, Hispaniola). Ottenwalderia kymbalion gen. et sp. nov. is the first lysianassoid known to have penetrated into completely fresh waters, and the fourth colonizing hypogean habitats. Bahadzia jaraguensis sp. nov. is the second representative of this West Indian thalasso-stygobiont genus to be reported from fresh waters; it exhibits the most troglomorphic aspect (i.e. elongation of first antennae and sixth pereiopods) recorded for the genus, Its diagnosis is complemented with a key to the species of the genus Bahadzia. The in situ swimming behaviour of both taxa is briefly described. It is postulated that both amphipods share a rather recent, Plio-Pleistocene marine origin, having invaded passively the continental waters in the way described by the so-called Regression model.
\end{abstract}

\section{Introduction}

The island of Hispaniola harbors one of the richer assemblages of stygobiont amphipods in the world. At least 13 species in 7 - five of them endemic genera of hadzioid, and two species of Bogidiellidae have been reported to date just from Haiti, which extends over $27.700 \mathrm{~km}^{2}$ on the western half of the island (Stock, 1985a; 1985b). The stygobiont amphipod fauna of the Dominican Republic (eastern half of Hispaniola; $48.443 \mathrm{~km}^{2}$ ) is still under study at present, but the first results of our mutual studies are published herein. The only mention of the presence of stygobiont amphipods in the Dominican Republic are in the lists of associated fauna accompanying the descriptions of the isopods Cyathura salpiscinalis Botosaneanu \& Stock, 1982, Cyathura broodbakkeri Wagner, 1990a, Cyathura tridentata Wagner, 1990a, Jehaia stocki Wagner, 1990b, and the thermosbaenacean Tethysbaena gaweini Wagner, 1994; however, no taxonomic assignment has been mentioned.

In this paper, we describe two new, cave-dwelling, stygobiont amphipods from the Pedernales Province of the Dominican Republic. Ottenwalderia kymbalion gen. et sp̃. nov. is noteworthy in being the first lysianassoid known to have penetrated into completely fresh waters, and the fourth to have colonized hypogean habitats. Bahadzia jaraguensis sp. nov, belongs to a stygobiont genus widely distributed in anchialine caves of raised salinity of the West Indian region.

Both taxa were collected from anchialine caves (sensu Stock et al., 1986) located near the shore line of Laguna de Oviedo, a hypersaline coastal lagoon of $25 \mathrm{~km}^{2}$ and about $11 \mathrm{~km}$ of maximum length in the vicinity of the town of Oviedo, inside the Jaragua National Park (Provincia de Pedernales). Ottenwalderia kymbalion was also found in a cave in the western part of the Pedernales Province near the Haitian border. The geologic basement of the zone consists of OligoceneMiocene limestone tabular outcrops deposited in a neritic environment, with a spectacular development of karstic phenomena (León, 1989). The lagoon was created after the sea invaded a huge karstic depression originated during a not yet specified regressive sea-level phase (León, loc. cit.). Caves along the shores of the lagoon have recently been reported by Trias et al. (1997). They are of modest dimensions, and their genesis might correspond to the same model proposed by Ginés \& Ginés (1992) for the Majorcan littoral caves, i.e.: (1) primary voids originating by dissolution in the littoral phreatic zone; (2) enlargement of voids by 
coastal, mixing-zone, cave forming mechanisms during sea-level transgressive phases; and (3) final phase of rock collapses affecting the vaults and walls of the cavities, often eliminating all traces of initial dissolution phases and causing their opening to the exterior through collapsed entrances. These caves are a few meters above the sea level, and many currently have their lower reaches flooded by the waters of the nearby lagoon. Others, further inland, harbor completely fresh waters. The region (less than $80 \mathrm{~m}$ above sea level) was very probably covered by the sea in rather recent times, bearing in mind the impressive series of PlioPleistocene marine terraces developed to the East of Cabo Rojo (see León, op. cit. and pers. obs.). Thus, the new taxa described below, of undoubted marine origin, are likely not to be older than that age.

The present study is dedicated to the memory of Prof. Dr. Jan H. Stock (22 February 1931-17 February 1997), pioneer in the study of the stygobiont amphipod fauna of Hispaniola.

\section{Materials and methods}

Both taxa were attracted by baited traps left for several days in the cave lakes, or gathered using a plankton net joined to a handle. Specimens were colored by Black B cuticular staining following the procedure described by Wagner (1994). Drawings were prepared using a camera lucida on an Olympus BH-2 microscope equipped with differential interference contrast. The terms used in descriptions follow Lincoln (1979) and Stock (1974; latter for setae on mandibular palp). Setal teeth on the outer plate of maxilla 1 are named following Lowry \& Stoddart (1997). Measurements refer to maximum distances between the margins of articles considered. Materials are deposited in the Museu de la Naturalesa de les Illes Balears, Palma de Mallorca (MNCM) and the Zoological Museum, Amsterdam (ZMA).

\section{Systematics}

Order Amphipoda Latreille, 1816

Family Lysianassidae Dana, 1849

Subfamily Tryphosinae Lowry \& Stoddart, 1997

Ottenwalderia gen. nov.

Diagnosis. - Calceoli absent from both antennae in both sexes. Peduncle of antenna 1 with articles subquadrate, progressively shorter, not compressed; first article slightly inflated; row of aesthetascs proximally on article 1 of flagellum, implanted beneath overhand of distal margin of third peduncular article. Weakly defined, 1-field callinophore on first antenna of both sexes. Mandibles lacking lacinia mobilis, with molar process triturative, having well-developed column. First maxilla with $[6+5]$ crown setal-tooth arrangement on the outer plate, with characteristic multicuspidate, comb-like STB, STC and STD; ST6 very broad, with concave, multicuspidate distomedial margin; ST7 displaced from ST6. Palp of first maxilla with distal serrations and robust setae. Outer plate of maxillipede with robust setae along distomedial margin. First gnathopod strongly subchelate, with tapering coxa. Uropod 3 of both sexes lacking plumose setae; outer ramus 1-articulate. Telson moderately cleft.

Type species. - Ottenwalderia sp. nov., here designated.

Etymology - The generic name is dedicated to José A. Ottenwalder, in recognition to his invaluable support during our fieldwork in the Dominican Republic.

Remarks. - This new taxon is placed in the subfamily Tryphosinae based on the triturative condition of the molar process of the mandible, the first maxilla with a $[6+5]$ crown setal-tooth arrangement on the outer plate and with terminal robust setae on the palp, the presence of robust setae on the apical margin of the outer plate of the maxillipede, the subchelate first gnathopod, and the cleft telson (see Lowry \& Stoddart, 1997). Within the Tryphosinae, only Tryphosella Bonnier, 1893, Lepiduristes Barnard \& Karaman, 1987 and the new taxon display strongly subchelate first gnathopods and tapering first coxae. However, they differ in important features supporting the erection of a new monotypic genus for the Hispaniolan taxon. Thus, in Tryphosella the propodus and dactylus of the first gnathopod have a very conservative condition (propodus elongate, subrectangular, with produced posterodistal corner resulting in con- 
cave palm margin; palm margin serrate; dactylus with large subterminal spine-like process) that is quite different to $O$. kymbalion. Besides, the mandible of Tryphosella has a lacinia mobilis, and the molar process has the column reduced; the setal teeth of the first maxilla have a very different shape (no comb-like setal teeth), and the outer ramus of the uropod 3 is 2 -articulate.

Lepiduristes differs in the very extended lateral lobes of the cephalon, hiding part of the peduncle of the second antenna; the peduncle of the first antenna has articles inflated, the first article forming a dorsal crest slightly overhanging articles 2 and 3; there is a lacinia mobilis on the mandible; the structure of gnathopod 1 is also different, with elongate ischium and with palm margin of propodus strongly oblique; and the outer ramus of uropod 3 is 2-articulate (Barnard, 1964; Barnard \& Karaman, 1987).

\section{Ottenwalderia kymbalion sp. nov. (Figs. 1-9)}

Material examined. - Prov. Pedernales, Oviedo, "El Agua de Odin', U.T.M, coordinates: 247400/1964750. Partial topography in Trias et al. (1997), where a small subrectangular chamber of $10 \times 4 \mathrm{~m}$ at $3 \mathrm{~m}$ inland from the western shore of Laguna de Oviedo is shown. This chamber continues landward along no less than $100 \mathrm{~m}$ of partially flooded passages connected to the exterior by at least 2 additional entrances. Brackish water, with appreciable diffuse flow. Holotype: $\%$ of $12.1 \mathrm{~mm}$ with developed oostegites (MNCM 348). Paratypes: hundreds of specimens, both sexes (MNCM 347 and ZMA 203882), collected by D. Jaume, 6 May 1997. Additional 21 specimens (MNCM 336), collected by D. Jaume, 14 July 1996.

-Prov. Pedernales, near Oviedo, "Cueva de los Bolos", U.T.M. coordinates: 246750/1967300. Cenote with large (about $52 \times$ $32 \mathrm{~m}$ ) entrance and $29 \mathrm{~m}$ deep to the waterline, at $1.2 \mathrm{~km}$ inland from the western shore of Laguna de Oviedo; chamber of $30 \times$ $14 \mathrm{~m}$ at the NW, with the lower reaches flooded by still, completely fresh water. Remnants of an old borehole pipe in the lake. This cave was the main watering place for the old town of Oviedo until the latter was devastated by a hurricane about 30 years ago. Hundreds of specimens, both sexes (MNCM 346), collected by D. Jaume, 10 May 1997. Accompanying fauna: Stygiomysis aemete Wagner, 1992; Bahadzia jaraguensis sp. nov; Cirolanidae; Cyclopidae.

- Prov. Pedernales, near Oviedo, "Pozímán Cadena", U.T.M. coordinates: $245200 / 1963600$. Cenote of ovoid, about $20 \times 13$ $\mathrm{m}$ entrance, and $21 \mathrm{~m}$ deep to the waterline. Small chamber located to the $\mathrm{W}$, completely occupied by shallow lake. Ten specimens (MNCM 342), collected by D. Jaume, 8 May 1997. Accompanying fauna: Stygiomysis aemete, Typhlatya sp.

Amsterdam Expeditions to the West Indian Islands, sta.
87/611: Prov. Pedernales, "Cueva Puente Sarnave", 17 $57^{\prime} 55^{\prime \prime}$ $N 71^{\circ} 38^{\prime \prime} 18^{\prime \prime} \mathrm{W}$. In pool of $6 \times 5 \mathrm{~m}$ located in a second chamber, which is $20 \mathrm{~m}$ from the main entrance, behind a narrow first chamber of $1 \times 1 \mathrm{~m}$ ), almost totally dark, bottom of medium sized stones on a hard surface covered with a thin layer of sandy coral rubble, water saturated by bauxite (redbrown color), temp. $26{ }^{\circ} \mathrm{C}$, oxygen saturation $68 \%$, electric conductivity $3.47 \mu \mathrm{S} /$ $\mathrm{cm}$. One specimen of $4.9 \mathrm{~mm}$ (ZMA 203882), collected by H.P. Wagner \& N.W. Broodbakker, 19 November 1987. Accompanying fauna: Gastropoda, Oligochaeta, insect larvae.

Description. - Sexes similar. Body (Fig. 1) up to $12.33 \mathrm{~mm}$, heavily built, capable of volvation. Troglobitization manifested only in absence of body pigment and visual apparatus, but not in elongation of appendages. Head with rostrum obsolete; lateral lobe evenly rounded; post-antennal sinus hardly developed. Body somites with surface devoid of robust setae except third pleonite, with 1 seta dorsolaterally at each side of telson (Fig. 2E).

Antenna 1 (Figs. 5A, B) lacking calceoli, short, with peduncle articles subquadrate, progressively shorter, not compressed; first article slightly inflated. Flagellum up to 19-articulate, first article with transverse row of long aesthetascs proximally on medial side, with insertion of aesthetascs partially hidden beneath overhand of distal margin of third peduncular article; weak 1-field callinophore in both sexes. Remaining flagellum articles each with 2 aesthetascs subdistally on posterior margin except 1-2 distal articles (lacking aesthetascs). Accessory flagellum 4 or 5-articulate, first article elongate, as long as 2 and 3 combined.

Antenna 2 (Fig. 5C) slender, a bit longer than antenna 1, lacking calceoli. Peduncle article 4 considerably longer than 5 ; gland cone well developed, pointing laterally. Flagellum up to $15-$ articulate, about as long as peduncle.

Upper lip (Figs. 2A, B) rounded in anterior view, with soft, rounded small flap midway along anterior margin. Epistome indistinct. Posterior surface of lip with setulose bulge. Lower lip (Fig. 2C) lacking inner lobes.

Mandibles (Fig. 2D) symmetrical, incisor with 3 low cusps. No trace of lacinia mobilis. Molar process (Fig. 2E) compact, columnar, column setose. - Proximolateral half of triturating surface formed by densely set, polygonal sclerotized plates; distomedial half densely spinulose. Three short, pointed processes on proximal margin; molar seta 
absent. Spine row between incisor and molar process composed of up to 3 barbed elements. Nonsclerotized curved process between incisor and palp; apex rounded. Mandibular palp 3-articulate; proximal article reduced; second article elongate, 4.8 times as long as wide, with subdistal row of up to 9 smooth setae along distoventral margin; distal article falcate, with 4 distal setae and sometimes with 1-2 D-setae. Surface of 2 distal articles of palp with rows of spinules.

Maxilla 1 (Fig. 3A) inner plate with 2 unequal setae on tip, longest plumose. Outer plate with distal group of $[6+5]$ sclerotized setal teeth. Number of cusps on setal teeth highly variable, even between right and left counterparts of same individual. ST1 to ST5 large, stout; ST1 and ST2 both uni- or bicuspidate; ST3 2 to 4-cuspidate; ST4 and ST5 each 3 to 5-cuspidate; ST6 large, very broad, 7 to 12-cuspidate along (concave) distomedial margin; ST7 displaced from ST6, large, 5 to 7-cuspidate medially, cusps elongate; STA somewhat reduced, displaced from STB, bi- or tricuspidate distally; STB to STD multicuspidate distally ( 8 to 12,8 to 15 , and 9 to 13 cusps, respectively), comb-like. Palp 2-articulate, surpassing clearly outer plate distally; distal article with distal margin serrate, with 4-5 robust setae partially embedded in article.

Maxilla 2 (Figs. 3B-D) inner plate slender, with 10-11 distal setae; outer plate longest, with 12 distal setae. Setae on both plates of heterogeneous morphology.

Maxillipede (Fig. 4A) with inner plate (Fig. 4B) more slender and shorter than outer plate, taper-

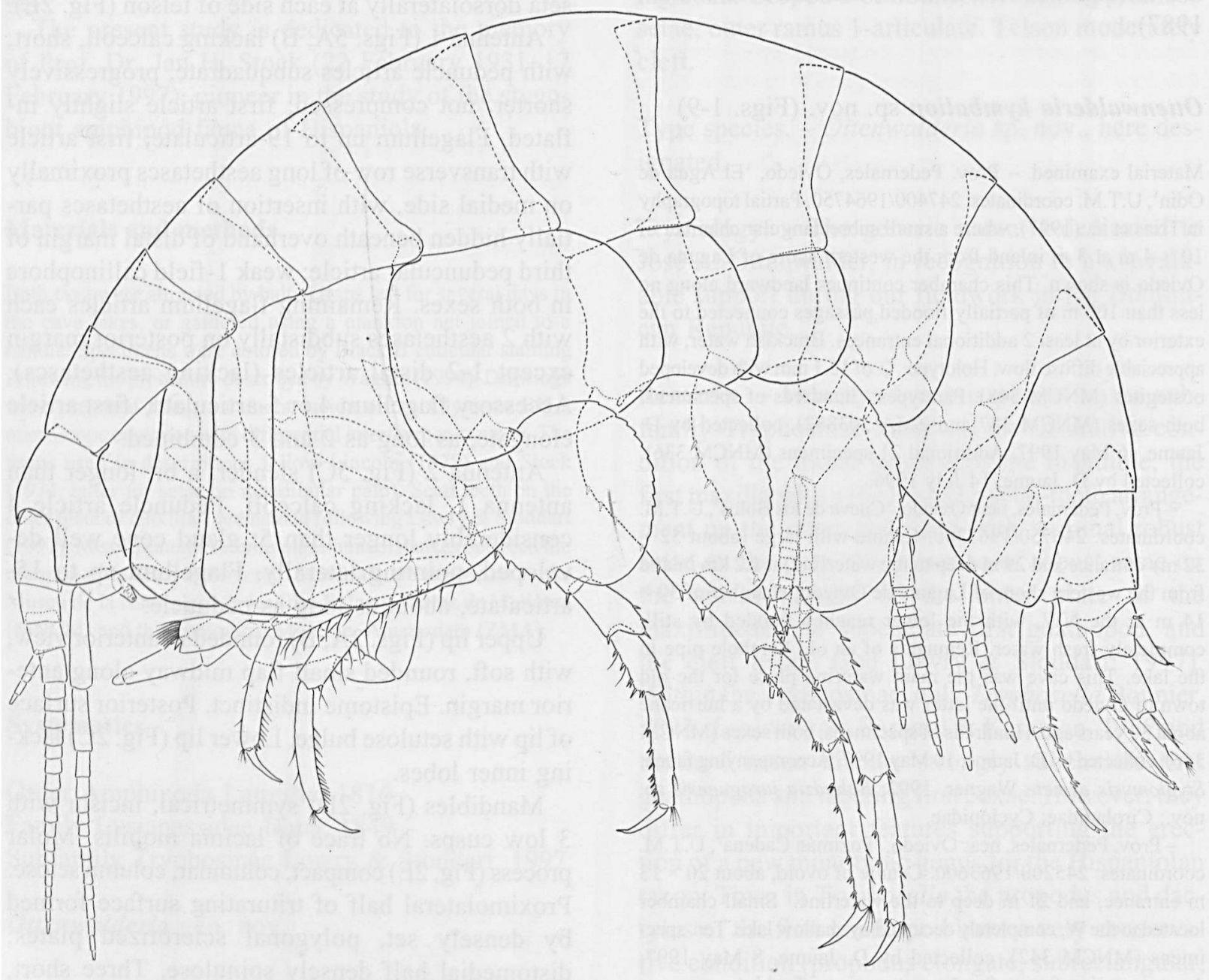

Fig. 1. Ottenwalderia kymbalion gen. et sp. nov.: habitus of $\odot$ of $10.7 \mathrm{~mm}$ (mouthparts and coxal gills omitted). 


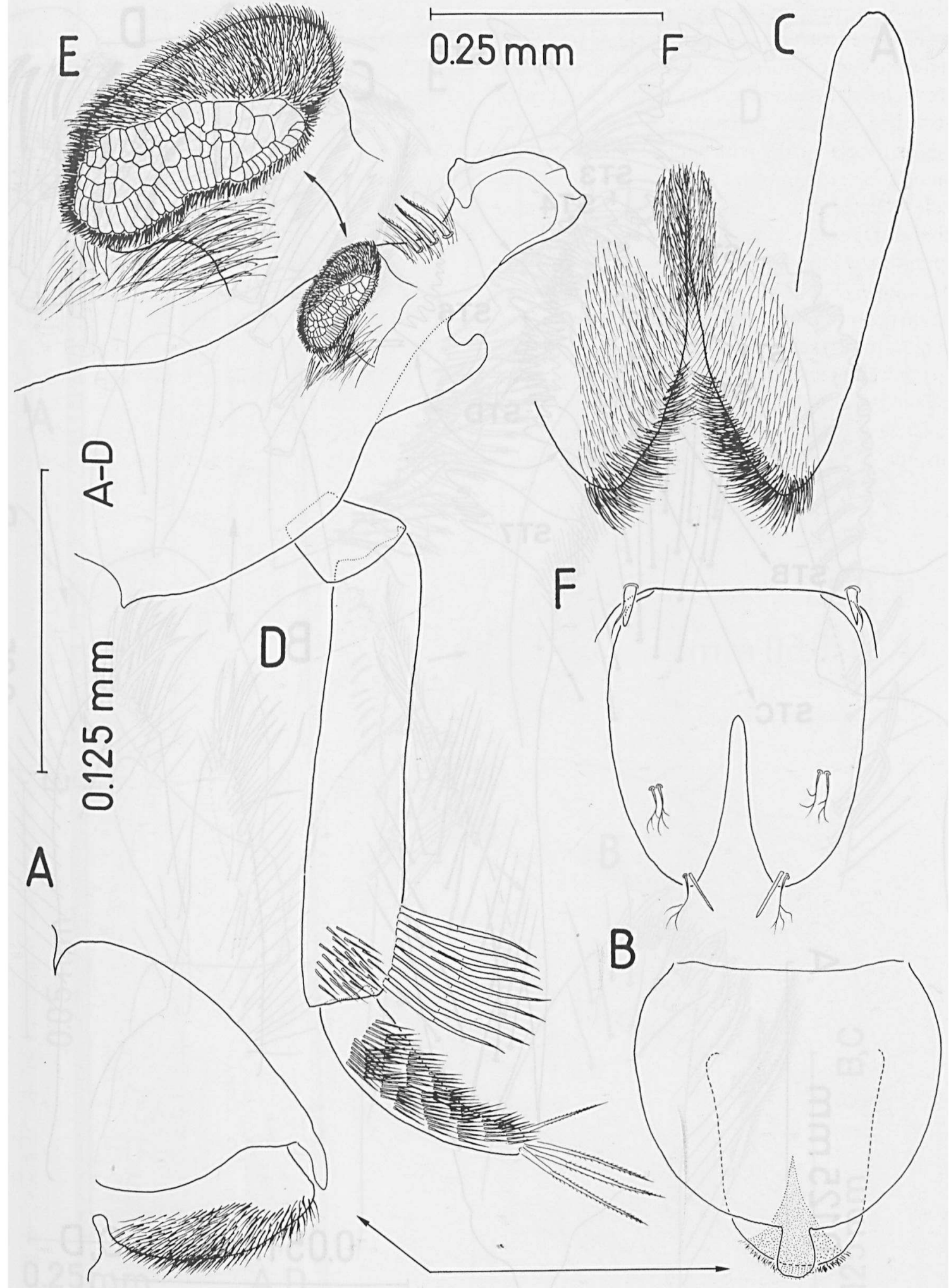

Fig. 2. Ottenwalderia kymbalion gen. et sp. nov., $९$ : A, upper lip, lateral; B, same, anterior; C, lower lip; D, right mandible; E, detail of molar process; $F$, telson, posterior. 


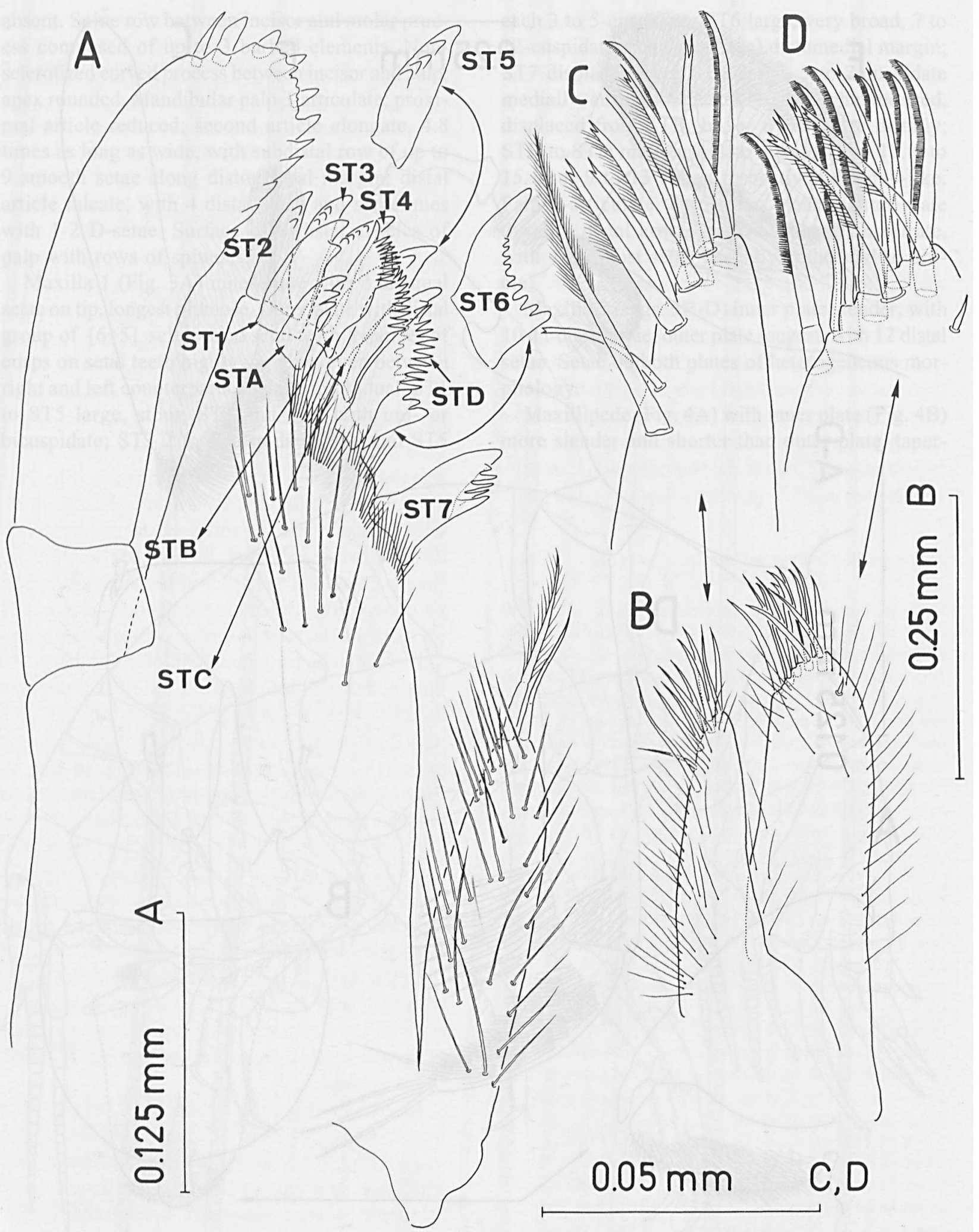

Fig. 3. Ottenwalderia kymbalion gen. et sp. nov., $\$$ : A, right maxilla 1, posterior (= ventral); B, maxilla 2; C, inner plate of maxilla 2 ; D, outer plate of maxilla 2. 


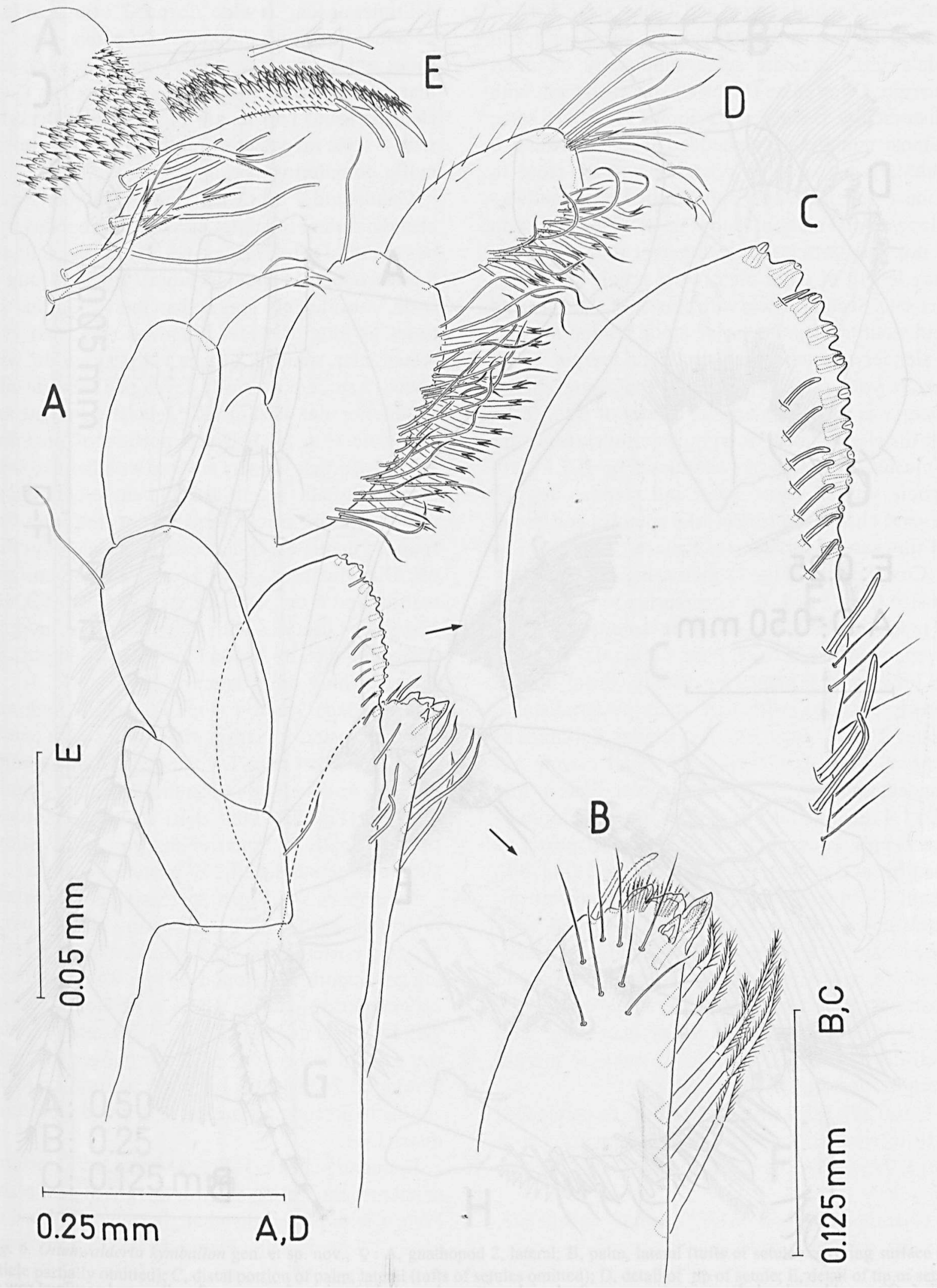

Fig. 4. Ottenwalderia kymbalion gen. et sp. nov., $\%:$ A, sketch of right maxillipede, posterior; B, distal portion of inner plate, posterior; C, distal portion of outer plate, posterior; D, distal articles of palp, posterior; E, detaibof orramentation on anteriornsurfaces $27 \mathrm{AM}$ of distal articles of (left) palp. * 


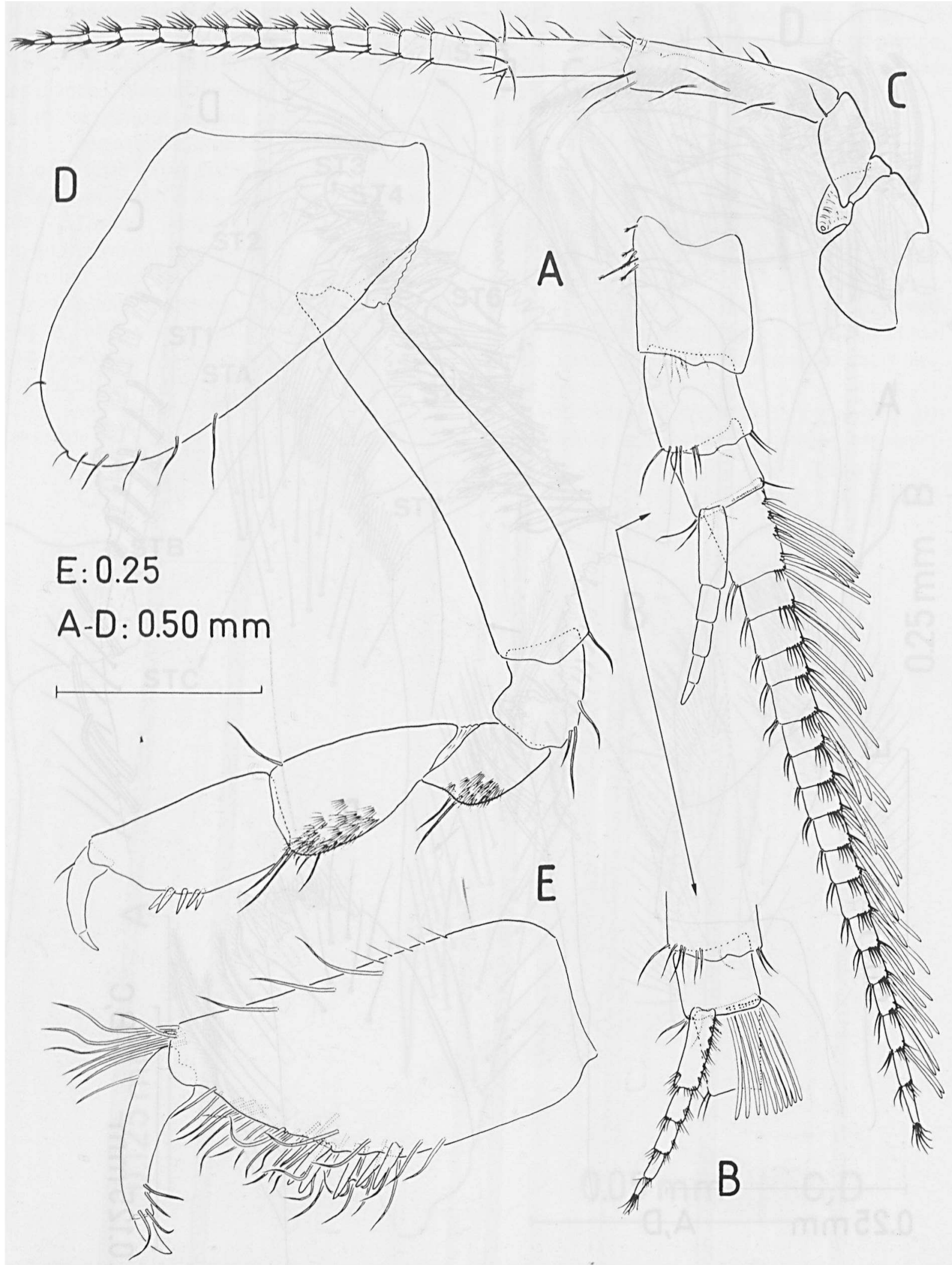

Fig. 5. Ottenwalderia kymbalion gen. et sp. nov., \&: A, right antenna 1, medial (setation of accessory flagellum and proximal row of aesthetascs on first article of flagellum omitted; insertion of latter aesthetases outlined beneath distal margin of third peduncular article); B, detail of setation of accessory flagellum and proximal row of aesthetascs on first articte of fflagellum; $\mathbb{C}_{4}$ left antentra 2;:27 AM lateral; D, gnathopod 1, lateral (setae on palm omitted); E, detail of palm, medial. 


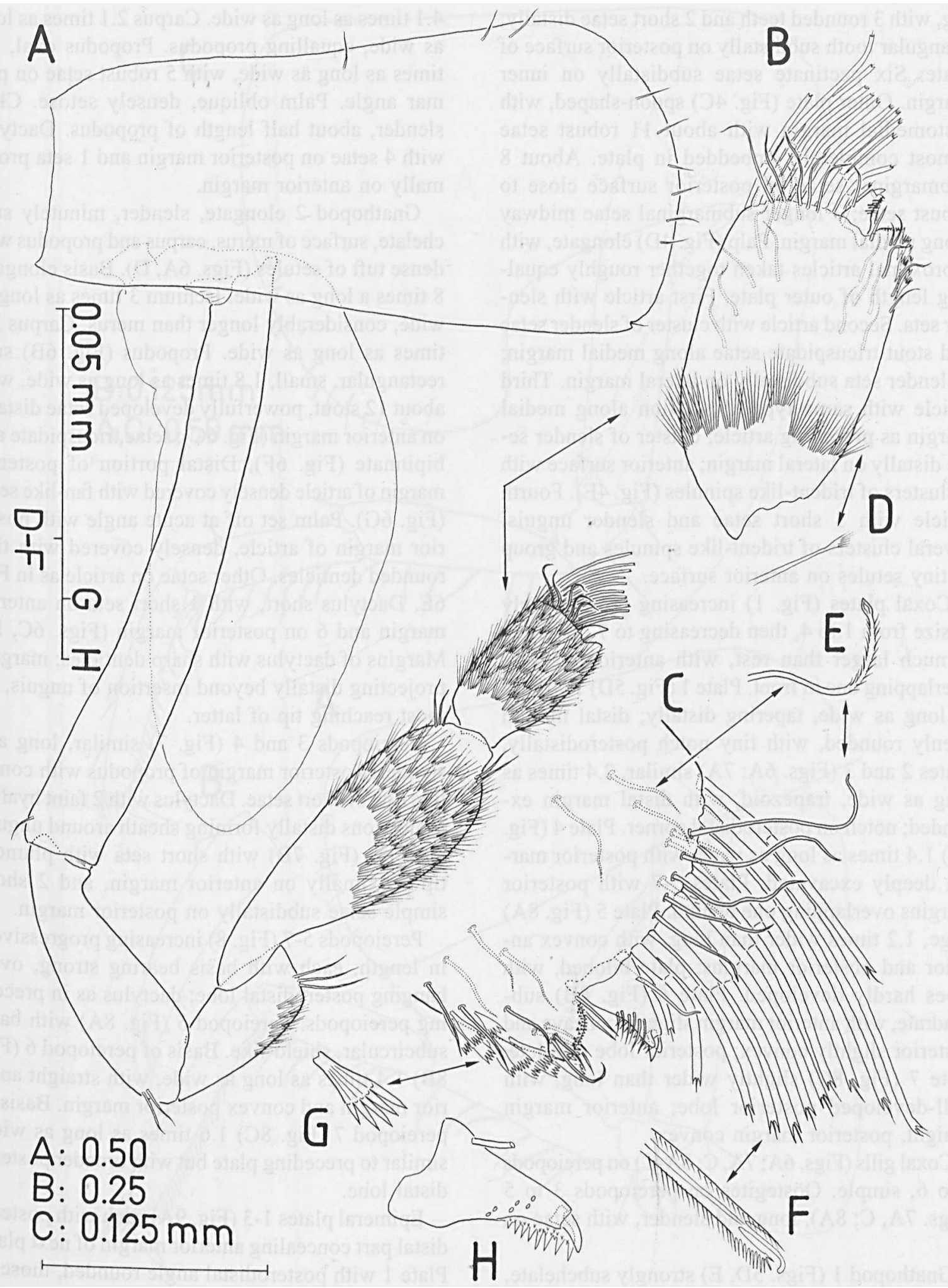

Fig. 6. Ottenwalderia kymbalion gen. et sp. nov., $\$:$ A, gnathopod 2, lateral; B, palm, lateral (tufts of setules covering surface of article partially omitted); C, distal portion of palm, lateral (tufts of setules omitted); D, detail of tip of setule; E, detail of tip of setae on propodus; F, detail of setae on anterodistal margin of propodus; G, detail of one of fan-like modified setae on posterodistal margin of palm; $\mathrm{H}$, claw, lateral (setae and outer margin projection of dactylus omitted). 
ing, with 3 rounded teeth and 2 short setae distally; triangular tooth subdistally on posterior surface of plate. Six pectinate setae subdistally on inner margin. Outer plate (Fig. 4C) spoon-shaped, with distomedial margin with about 11 robust setae almost completely embedded in plate. About 8 submarginal setae on posterior surface close to robust setae; 3 longer submarginal setae midway along medial margin. Palp (Fig. 4D) elongate, with 2 proximal articles taken together roughly equalling length of outer plate. First article with slender seta. Second article with cluster of slender setae and stout tricuspidate setae along medial margin; 1 slender seta subdistally on lateral margin. Third article with same type of setation along medial margin as preceding article; cluster of slender setae distally on lateral margin; anterior surface with 2 clusters of trident-like spinules (Fig. 4E). Fourth article with 3 short setae and slender unguis; several clusters of trident-like spinules and group of tiny setules on anterior surface.

Coxal plates (Fig. 1) increasing progressively in size from 1 to 4 , then decreasing to 7 . Plates 1 4 much larger than rest, with anterior margins overlapping one in front. Plate 1 (Fig. 5D) 1.7 times as long as wide, tapering distally; distal margin evenly rounded, with tiny notch posterodistally. Plates 2 and 3 (Figs. 6A; 7A) similar, 2.4 times as long as wide, trapezoid, with distal margin expanded; notch on posterodistal corner. Plate 4 (Fig. 7C) 1.4 times as long as wide, with posterior margin deeply excavated. Plates 5-7 with posterior margins overlapping one behind. Plate 5 (Fig. 8A) large, 1.2 times wider than long, with convex anterior and posterior margins; plate bilobed, with lobes hardly developed. Plate 6 (Fig. 8B) subquadrate, with anterior margin slightly concave and posterior slightly convex; posterior lobe obsolete. Plate 7 (Fig. 8C) slightly wider than long, with well-developed posterior lobe; anterior margin straight, posterior margin convex.

Coxal gills (Figs. 6A; 7A, C; 8A-C) on pereiopods 2 to 6 , simple. Oöstegites on pereiopods 3 to 5 (Figs. 7A, C; 8A), long and slender, with setae on tip.

Gnathopod 1 (Figs. 5D, E) strongly subchelate, slender, with tufts of long setules partially covering surface of merus and carpus. Basis elongate,
4.1 times as long as wide. Carpus 2.1 times as long as wide, equalling propodus. Propodus oval, 2.1 times as long as wide, with 5 robust setae on palmar angle. Palm oblique, densely setose. Claw slender, about half length of propodus. Dactylus with 4 setae on posterior margin and 1 seta proximally on anterior margin.

Gnathopod 2 elongate, slender, minutely subchelate, surface of merus, carpus and propodus with dense tuft of setules (Figs. 6A, D). Basis elongate, 8 times a long as wide. Ischium 3 times as long as wide, considerably longer than merus. Carpus 2.9 times as long as wide. Propodus (Fig. 6B) subrectangular, small, 1.8 times as long as wide, with about 12 stout, powerfully developed setae distally on anterior margin (Fig. 6C); setae tricuspidate and bipinnate (Fig. 6F). Distal portion of posterior margin of article densely covered with fan-like setae (Fig. 6G). Palm set off at acute angle with posterior margin of article, densely covered with tiny rounded denticles. Other setae on article as in Fig. 6E. Dactylus short, with 1 short seta on anterior margin and 6 on posterior margin (Figs. $6 \mathrm{C}, \mathrm{H}$ ). Margins of dactylus with sharp denticles; margins projecting distally beyond insertion of unguis, almost reaching tip of latter.

Pereiopods 3 and 4 (Fig. 7) similar, long and slender. Posterior margin of propodus with comblike row of short setae. Dactylus with 2 faint hyaline projections distally forming sheath around unguis; dactylus (Fig. 7B) with short seta with plumose tip proximally on anterior margin, and 2 short, simple setae subdistally on posterior margin.

Pereiopods 5-7 (Fig. 8) increasing progressively in length, each with basis bearing strong, overhanging posterodistal lobe; dactylus as in preceding pereiopods. Pereiopod 5 (Fig. 8A) with basis subcircular, shield-like. Basis of pereiopod 6 (Fig. 8B) 1.4 times as long as wide, with straight anterior margin and convex posterior margin. Basis of pereiopod 7 (Fig. 8C) 1.6 times as long as wide, similar to preceding plate but with broader posterodistal lobe.

Epimeral plates 1-3 (Fig. 9A) each with posterodistal part concealing anterior margin of next plate. Plate 1 with posterodistal angle rounded, those of plates 2-3 more acute. Pleopods 1-3 (Fig. 9B) well developed, similar, outer ramus with up to 21 arti- 


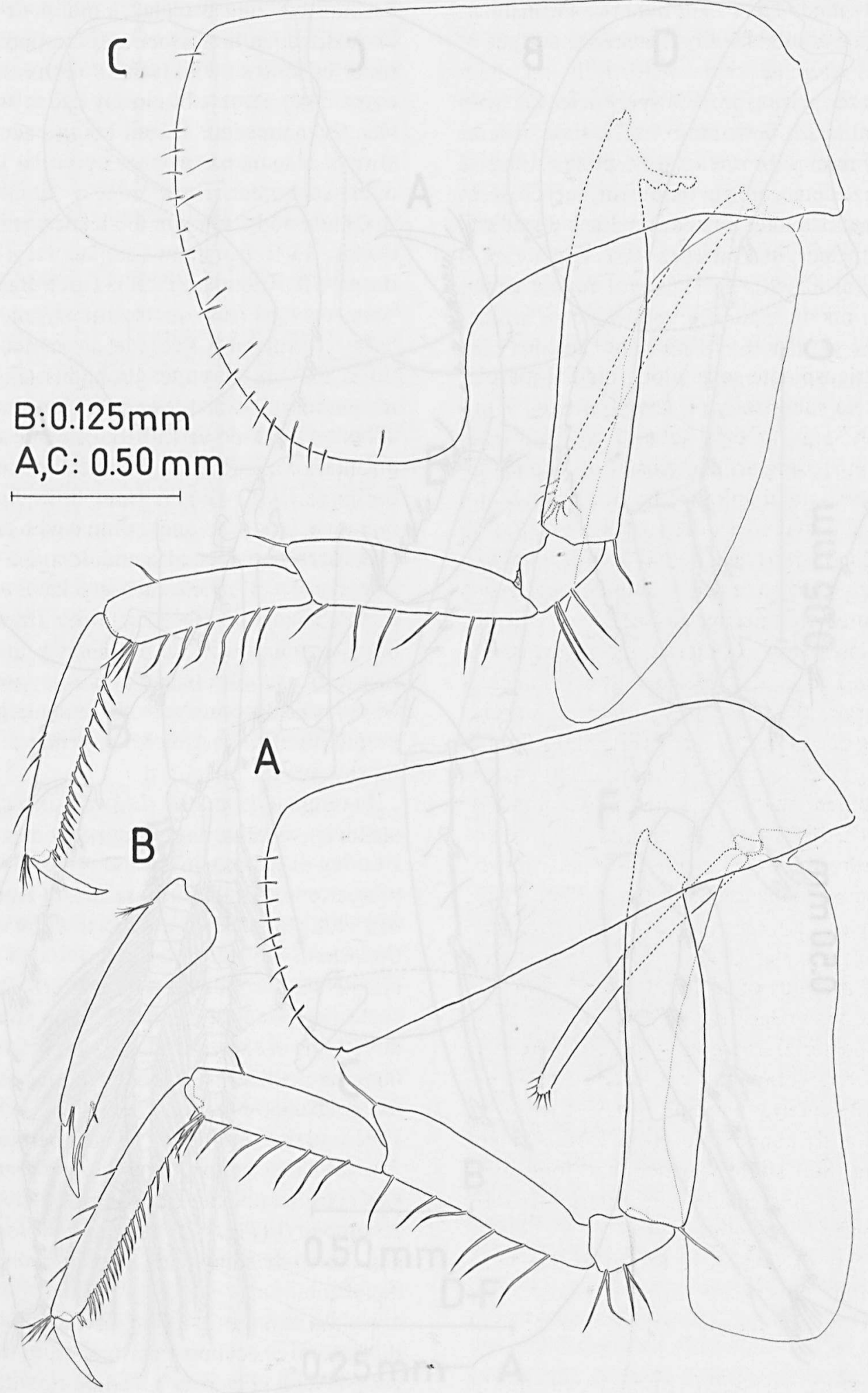

Fig. 7. Ottenwalderia kymbalion gen. et sp. nov., $९$ : A, pereiopod 3; B, detail of claw; C, pereiopod 4. 


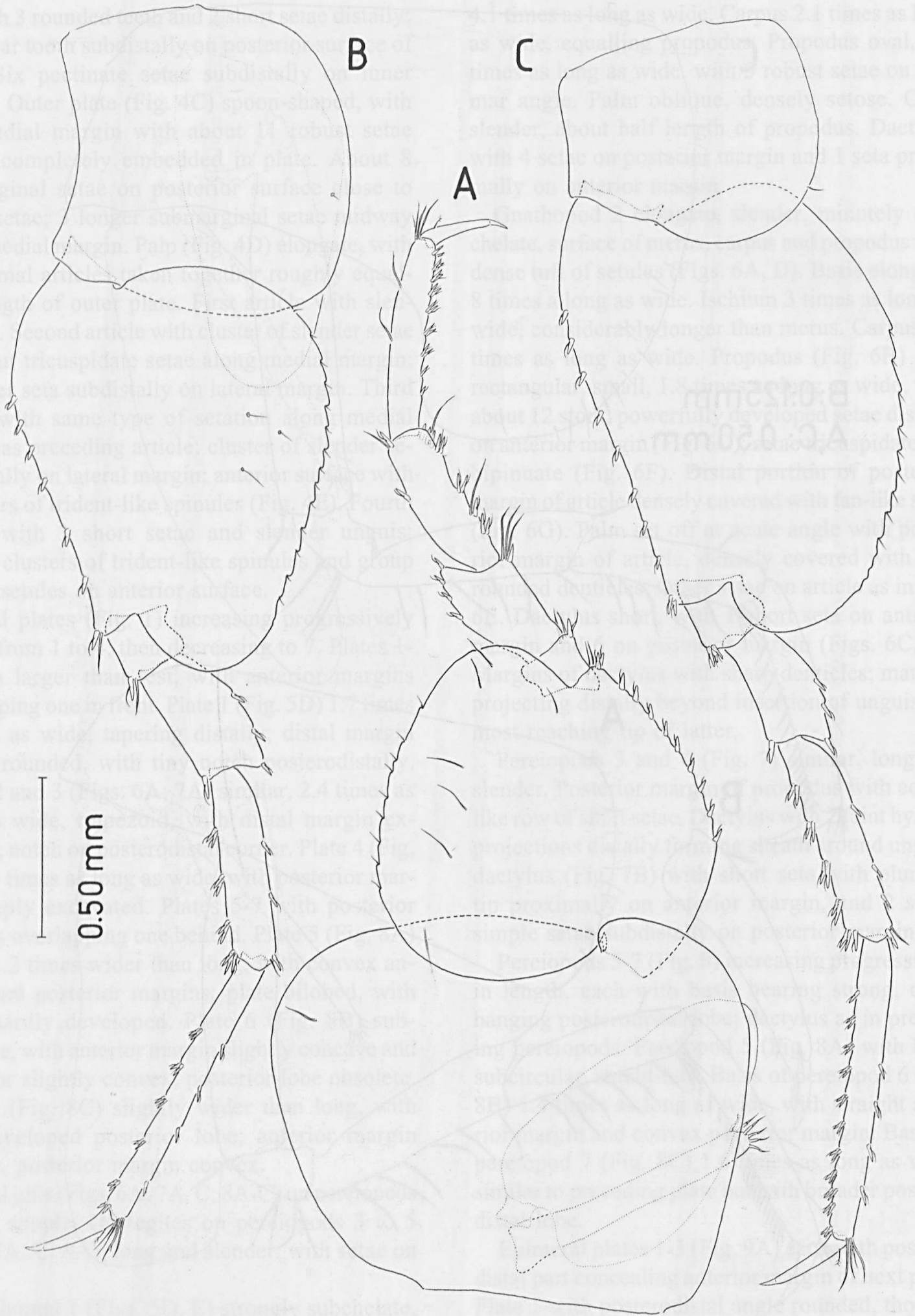

Fig. 8. Ottenwalderia kymbalion gen. et sp. nov., ९: A, pereiopod 5; B, pereiopod 6; C, pereiopod 7. 


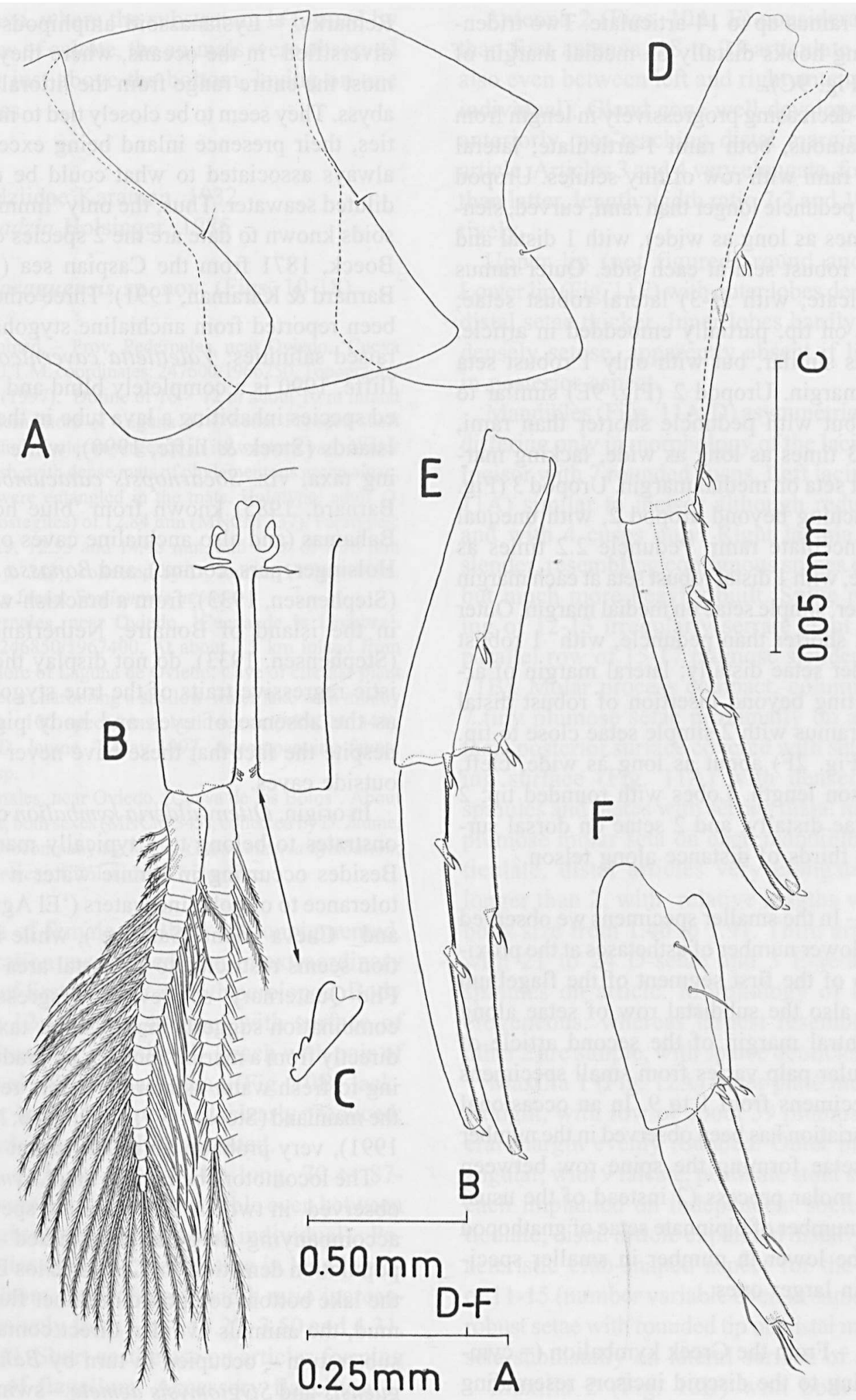

Fig. 9. Ottenwalderia kymbalion gen. et sp. nov., ९ : A, epimeral plates; B, right pleopod 1, anterior; C, detail of coupling hook; D, left uropod 1, lateral; E, left uropod 2, lateral; F, right uropod 3, medial. 
cles, inner ramus up to 14-articulate. Two tridentate coupling hooks distally on medial margin of peduncle (Fig. 9C).

Uropods decreasing progressively in length from 1 to 3 , biramous, both rami 1-articulate; lateral margins of rami with row of tiny setules. Uropod 1 (Fig. 9D) peduncle longer than rami, curved, slender (4.7 times as long as wide), with 1 distal and 1 marginal robust seta at each side. Outer ramus slender, falcate, with 2(-3) lateral robust setae; robust seta on tip, partially embedded in article. Inner ramus similar, but with only 1 robust seta on lateral margin. Uropod 2 (Fig. 9E) similar to uropod 1, but with peduncle shorter than rami, straight, 3.3 times as long as wide, lacking marginal robust seta on medial margin. Uropod 3 (Fig. 9F) not reaching beyond uropod 2, with unequal laminar, lanceolate rami. Peduncle 2.2 times as long as wide, with 1 distal robust seta at each margin plus 3 slender, simple setae on medial margin. Outer ramus a bit shorter than peduncle, with 1 robust and 3 slender setae distally; lateral margin of article projecting beyond insertion of robust distal seta. Inner ramus with 2 simple setae close to tip.

Telson (Fig. 2F) about as long as wide, cleft, $57 \%$ of telson length. Lobes with rounded tip; 2 unequal setae distally, and 2 setae on dorsal surface at two thirds of distance along telson.

Variability - In the smaller specimens we observed generally a lower number of asthetascs at the proximal portion of the first segment of the flagellum of $\mathrm{A1}$, and also the subdistal row of setae along the distoventral margin of the second article of the mandibular palp varies from small specimens to large specimens from 1 to 9 . In an occasional specimen variation has been observed in the number of barbed setae forming the spine row between incisor and molar process ( 2 instead of the usual 3). Also the number of bipinnate setae of gnathopod 2 tends to be lower in number in smaller specimens than in larger ones.

Etymology. - From the Greek kymbalion (= cymbals), alluding to the discoid incisors resembling two opposing brass plates used as a musical instrument.
Remarks. - Lysianassoid amphipods are widely diversified in the oceans, where they occupy almost the entire range from the littoral zone to the abyss. They seem to be closely tied to marine salinities, their presence inland being exceptional and always associated to what could be qualified as diluted seawater. Thus, the only 'limnic' lysianassoids known to date are the 2 species of Onisimus Boeck, 1871 from the Caspian sea (Sars, 1896; Barnard \& Karaman, 1991). Three other taxa have been reported from anchialine stygohabitats with raised salinities: Valettietta cavernicola Stock \& Iliffe, 1990 is a completely blind and unpigmented species inhabiting a lava tube in the Galápagos Islands (Stock \& Iliffe, 1990), while the remaining taxa, viz. Socarnopsis catacumba (Clark \& Barnard, 1985) known from 'blue holes' in the Bahamas (and also anchialine caves on Cozumel; Holsinger, pers. comm.), and Bonassa bonairensis (Stephensen, 1933), from a brackish-water cistern in the island of Bonaire, Netherlands Antilles (Stephensen, 1933), do not display the characteristic regressive traits of the true stygobionts such as the absence of eyes and body pigmentation, despite the fact that these have never been found outside caves.

In origin, Ottenwalderia kymbalion clearly demonstrates to belong to a typically marine family. Besides occurring in limnic water it also shows tolerance to oligohaline waters ('El Agua de Odín" and 'Cueva Puente Sarnave'), while its distribution seems restricted to a coastal area covered by Plio-Quaternary sea-level transgressions. This combination suggests that this new taxon evolved directly from a marine ancestor by gradually adapting to fresh water as marine waters receded from the mainland (Stock, 1977; 1980; 1986; Notenboom, $1991)$, very probably in rather recent times.

The locomotory behaviour of $O$. kymbalion was observed in two caves, where the species and its accompanying stygofauna attained impressive population densities. In 'Cueva de los Bolos', with the lake bottom composed of rather fluid, epipelic mud, the animals avoided direct contact with the substratum - occupied in turn by Bahadzia jaraguensis and Stygiomysis aemete - swimming constantly with the ventral side of the body turned backwards across the water column. In 'El Agua 
de Odin' cave, where the substratum is formed by coarse grains of calcite, the animals were observed progressing just above the bottom, laying on one of their sides.

Family Hadziidae Karaman, 1932

Genus Bahadzia Holsinger, 1985

Bahadzia jaraguensis sp. nov. (Figs. 10-18)

Material examined. - Prov. Pedernales, near Oviedo, "Cueva de Mondesi' . U.T.M. coordinates: 247600/1966250. Topography in Trias et al. (1997). Doline of $16 \times 12 \mathrm{~m}$ about $10 \mathrm{~m}$ inland from the western shore of Laguna de Oviedo. Flooded shaft harboring an underwater resurgence in its westem part. Water weakly brackish, with dense mats of phylamentous green algae. The animals were entangled in the mats. Holotype: adult 9 (with setose oostegites) of 12.84 mm (MNCM 337). Paratypes: $3 \%$ of $12.19,12.53$ and $14.48 \mathrm{~mm}$, and $1 \sigma^{\circ}$ of $9.76 \mathrm{~mm}$ (MNCM 338 to 341), collected by D. Jaume, 10 July 1996. Accompanying fauna: Stygiomysis aemete.

- Prov. Pedernales, near Oviedo, "Cueva de la Lechosa". Coordinates: 246850/1967400, At about $1.1 \mathrm{~km}$ inland from the western shore of Laguna de Oviedo. Cave of circular plant ( $10 \mathrm{~m}$ diameter) harboring a shallow-water lake with muddy bottom. About 100 specimens, both sexes (MNCM 344), collected by D. Jaume, 7 May 1997. Accompanying fauna: Tethysbaena sp.

- Prov. Pedernales, near Oviedo, "Cueva de los Bolos". About 100 specimens, both sexes (MNCM 345), collected by D. Jaume, 7 May 1997. Accompanying fauna: Ottenwalderia kymbalion; Stygiomysis aemete; Cirolanidae; Cyclopidae.

Description of female. - Blind and unpigmented. Troglobitization manifested also in extraordinary elongation of first antenna and 6 th pereiopod. Body (Fig. 10A) 12.19 to $14.48 \mathrm{~mm}$, with surface of somites pubescent; pleonites 1-3 each with pair of posterodorsal robust setae. Head (Fig. 10B) lacking rostrum; lateral lobe rounded, clearly produced; postantennal sinus hardly excavated.

Antenna 1 (Figs. 10A, C, D) long, 70 to 87articulate (number of articles variable even between left and right antennae of same individual). Peduncle articles elongate, decreasing in length progressively from 1 to 3 ; length:width ratio increasing progressively from 1 to $3(3.27,3.50$ and 4.31 , respectively). Short aesthetasc on articles forming distal half of flagellum. Accessory flagellum 3articulate, 2 proximal articles long and slender, distal reduced.
Antenna 2 (Figs. 10A, E) considerably shorter than first antenna, 18 to 23-articulate (variability also even between left and right antennae of same individual). Gland cone well developed, pointing anteriorly, not reaching distal margin of second article. Articles 3 and 4 very elongate, former longer than latter, length:width ratio 7.7 and 10.0 , respectively.

Upper lip (not figured) round and flattened. Lower lip (Fig. 11E) with outer lobes densely setose; distal setae thicker. Inner lobes hardly developed, densely setose, apparently absent if lip observed in posterior aspect.

Mandibles (Figs. 11A-D) asymmetrical, although differing only in morphology of the lacinia mobilis. Incisor with 7 rounded cusps. Left lacinia (see Fig. 11A) similar to incisor although reduced in size and with 4 cusps only. Right lacinia (Fig. 11D) slender, resembling contiguous spines of spine row but much more heavily built. Spine row consisting of 12-13 irregularly serrate stout spines plus parallel row of 15-17 plumose slender setae (Fig. 11B). Molar process compact, columnar, with 57 tiny plumose setae proximally on anterior surface; posterior surface covered with setules. Grinding surface (Fig. 11A) with densely set short spinules and plates with serrate distal margin. Long plumose molar seta on each mandible. Palp 3-articulate, distal artícles very elongate. Article 3 longer than 2 , with relative lengths varying with body size from 1.46 to 1.91 . Third article falcate, with 21 to 24 D-setae and 3 E-setae; patch of spinules on article. Morphology of E-setae heterogeneous: whereas largest resembles D-setae, other 2 are simple, with sparse denticles (Fig. 11C).

Maxilla 1 (Fig. 12A) inner plate medial margin straight, with row of about 39 plumose setae; lateral margin evenly rounded. Outer plate subrectangular, with 9 falcate, pectinate stout setae distally, each implanted on independent socle. Palp 2-articulate, distal article expanded distally, with characteristic club-shaped aspect for the genus; row of 11-15 (number variable even in same individual) robust setae with rounded tip on distal margin; single seta subdistally on lateral surface of article.

Maxilla 2 (Fig. 12B) with both plates subrectangular. Inner plate slender, setae concentrated on tip, roughly forming 3 rows. Setae of 3 differ- 


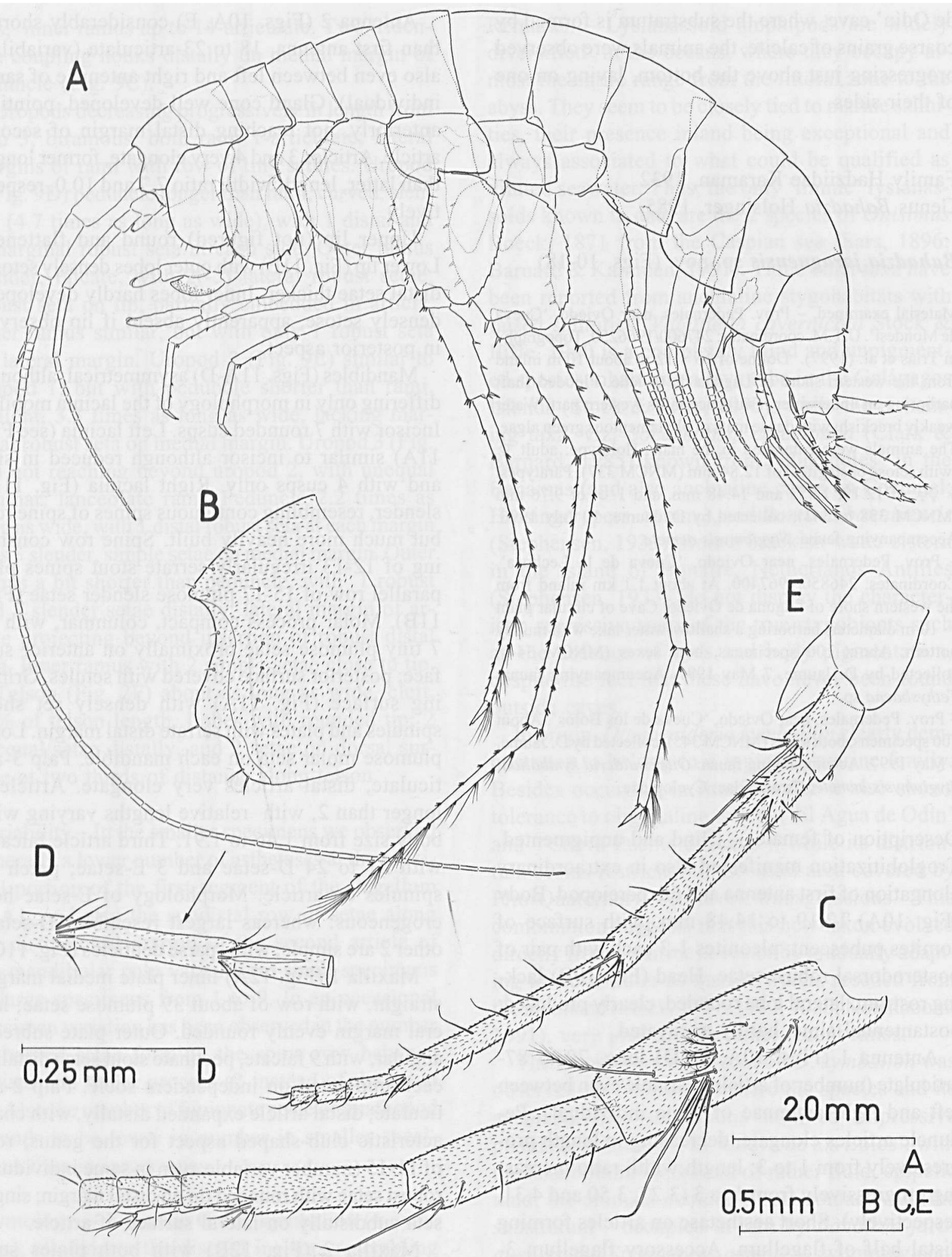

Fig. 10. Bahadzia jaraguensis sp. nov., \&: A, body, lateral (mouthparts and oostegites omitted); B, head, lateral; C, proximal part of antenna $1 ; \mathrm{D}$, armature on distal articles of antenna $1 ; \mathrm{E}$, proximal articles of antenna 2. 


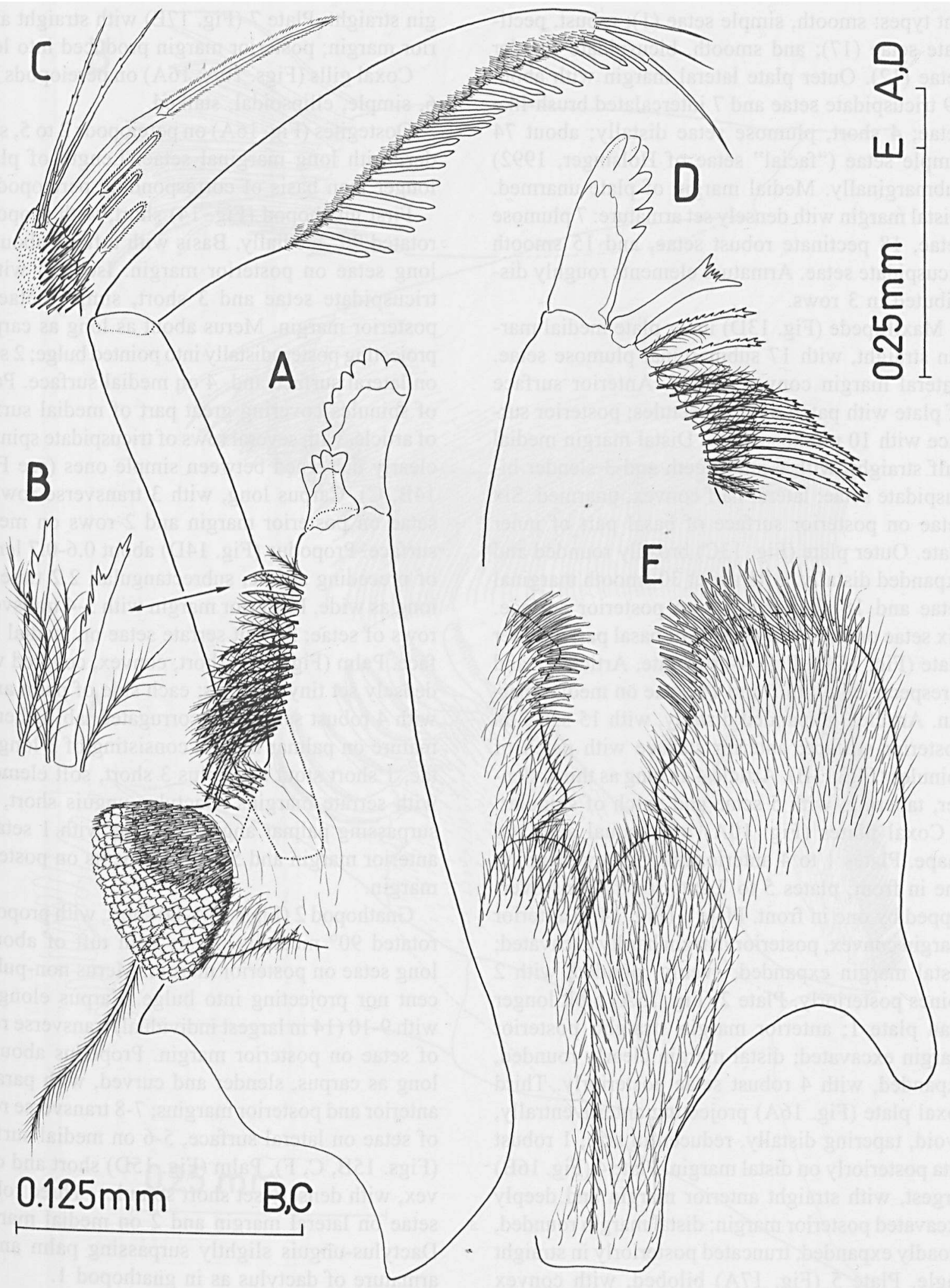

Fig. 11. Bahadzia jaraguensis sp. nov., $\odot:$ A, left mandible; B, detail of spine row; $\mathrm{C}$, tip of palp; D, distal portion of right mandible; $\mathrm{E}$, lower lip, anterior. 
ent types: smooth, simple setae (1); robust, pectinate setae (17); and smooth, bicuspidate slender setae (12). Outer plate lateral margin with about 19 tricuspidate setae and 7 intercalated brush-like setae; 4 short, plumose setae distally; about 74 simple setae ("facial" setae of Holsinger, 1992) submarginally. Medial margin of plate unarmed. Distal margin with densely set armature: 7 plumose setae, 18 pectinate robust setae, and 15 smooth bicuspidate setae. Armature elements roughly distributed in 3 rows.

Maxillipede (Fig. 13D) inner plate medial margin straight, with 17 submarginal plumose setae. Lateral margin convex, naked. Anterior surface of plate with patch of small setules; posterior surface with 10 plumose setae. Distal margin medial half straight, with 6 stout teeth and 3 slender bicuspidate setae; lateral half convex, unarmed. Six setae on posterior surface of basal part of inner plate. Outer plate (Fig. 13C) broadly rounded and expanded distally, with about 30 smooth marginal setae and 18 shorter setae on posterior surface. Six setae on posterior surface of basal part of outer plate (Fig. 13A). Palp 4-articulate. Articles 1 and 2 respectively with 2 and 11 setae on medial margin. Article 3 expanded distally, with 15 setae on posterior surface; anterior surface with patch of spinules (Fig. 13B). Article 4 as long as third, slender, tapering, with 5 setae and patch of spinules.

Coxal plates (Fig. 10A) of unequal size and shape. Plates 1 to 4 anterior margins overlapping one in front; plates 5 to 7 anterior margins overlapped by one in front. Plate 1 (Fig. 14A) anterior margin convex, posterior margin hardly excavated; distal margin expanded, evenly rounded, with 2 spines posteriorly. Plate 2 (Fig. 15A) a bit longer than plate 1; anterior margin straight, posterior margin excavated; distal margin clearly rounded, expanded, with 4 robust setae posteriorly. Third coxal plate (Fig. 16A) projecting anteroventrally, ovoid, tapering distally, reduced in size; 1 robust seta posteriorly on distal margin. Plate 4 (Fig. 16B) largest, with straight anterior margin and deeply excavated posterior margin; distal margin rounded, broadly expanded, truncated posteriorly in straight angle. Plate 5 (Fig. 17A) bilobed, with convex anterior and posterior margins. Plate 6 (Fig. 17C) similar to preceding plate but with anterior mar- gin straight. Plate 7 (Fig. 17E) with straight anterior margin; posterior margin produced into lobe.

Coxal gills (Figs. 10A; 16A) on pereiopods 2 to 6, simple, ellipsoidal, stalked.

Oostegites (Fig. 16A) on pereiopods 2 to 5 , slender, with long marginal setae. Length of plates longer than basis of corresponding pereiopod.

First gnathopod (Fig. 14) short, with propodus rotated $90^{\circ}$ medially. Basis with tuft of about 16 long setae on posterior margin. Ischium with 3 tricuspidate setae and 3 short, simple setae on posterior margin. Merus about as long as carpus, projecting posterodistally into pointed bulge; 2 setae on lateral surface and 4 on medial surface. Patch of spinules covering great part of medial surface of article, with several rows of tricuspidate spinules clearly discerned between simple ones (see Figs. 14B, C). Carpus long, with 3 transverse rows of setae on posterior margin and 2 rows on medial surface. Propodus (Fig. 14D) about 0.6-0.7 length of preceding article, subrectangular, 2.2 times as long as wide. Posterior margin with 3-4 transverse rows of setae; 2 stout serrate setae on medial surface. Palm (Fig. 14E) short, convex, covered with densely set tiny spinules; each side of palm angle with 4 robust setae with corrugated tab. Other armature on palmar margin consisting of 3 long setae, 1 short stout seta, plus 3 short, soft elements with serrate margins. Dactylus-unguis short, not surpassing palmar angle; dactylus with 1 seta on anterior margin and 5 short elements on posterior margin.

Gnathopod 2 (Figs. 15A-D) short, with propodus rotated $90^{\circ}$ medially. Basis with tuft of about 7 long setae on posterior margin. Merus non-pubescent nor projecting into bulge. Carpus elongate, with 9-10 (14 in largest individual) transverse rows of setae on posterior margin. Propodus about as long as carpus, slender and curved, with parallel anterior and posterior margins; 7-8 transverse rows of setae on lateral surface, 5-6 on medial surface (Figs. 15B, C, F). Palm (Fig. 15D) short and convex, with densely set short spinules. Three robust setae on lateral margin and $\mathbf{2}$ on medial margin. Dactylus-unguis slightly surpassing palm angle; armature of dactylus as in gnathopod 1.

Pereiopods 3 and 4 (Fig. 16) elongate, subsimilar (except for coxal plates; see above). Appendages 

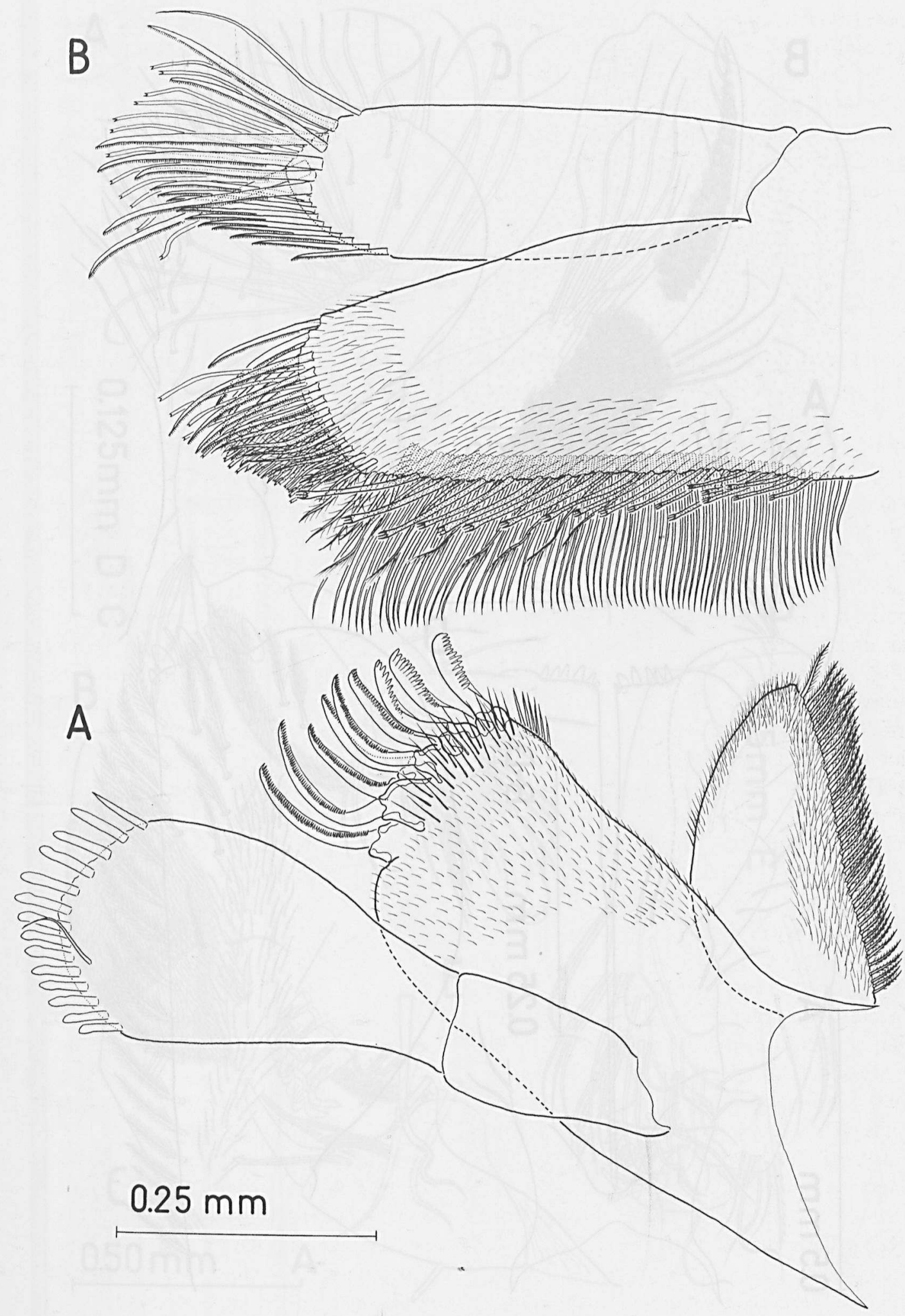

Fig.12. Bahadzia jaraguensis sp. nov., ९: A, first maxilla, lateral; B, second maxilla. 


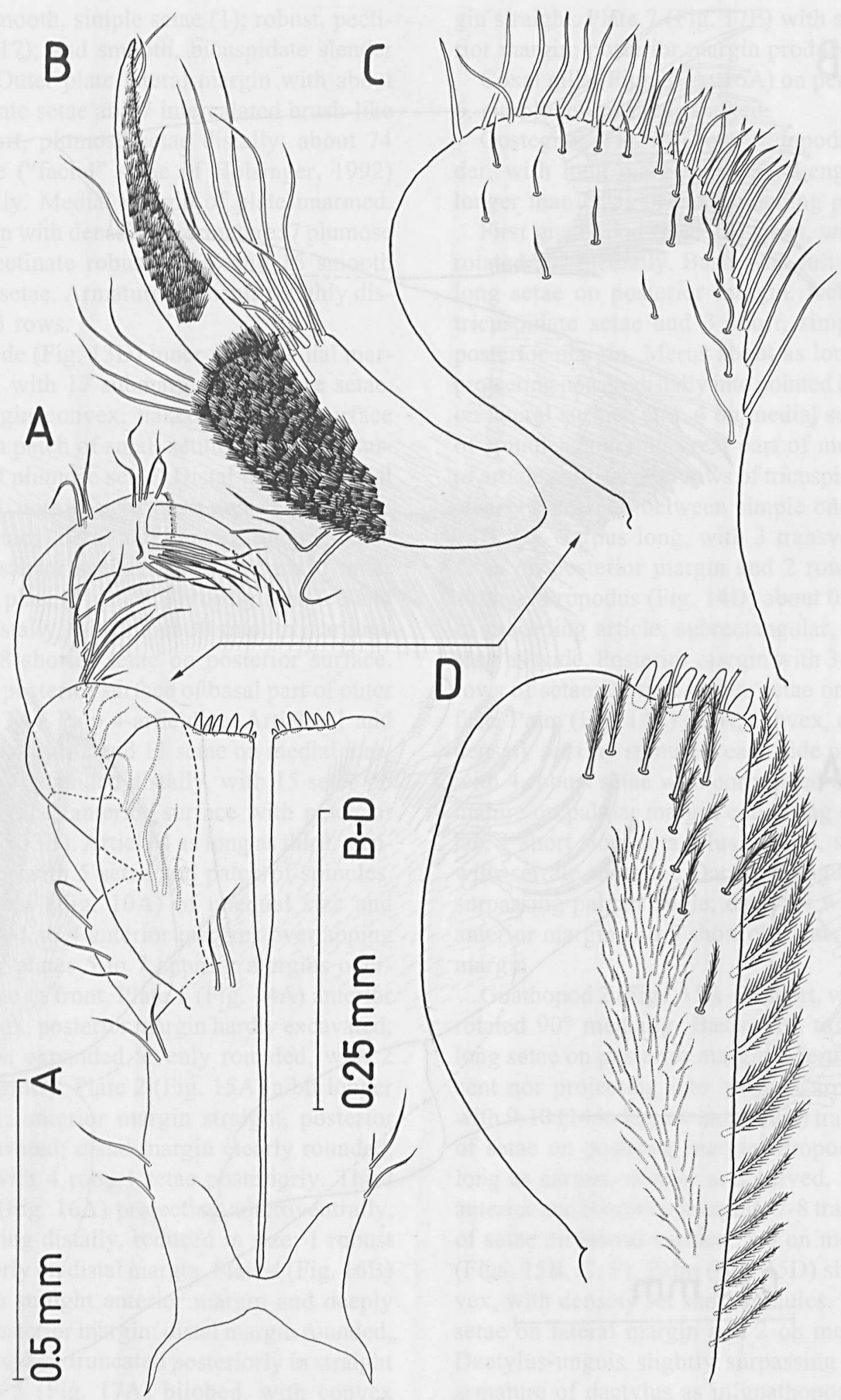

Fig.13. Bahadzia jaraguensis sp. nov., ९: A, maxillipede, posterior (armature on inner and outer plates omitted); B, distal articles of palp, anterior; C, outer plate, posterior; D, inner plate, posterior. 


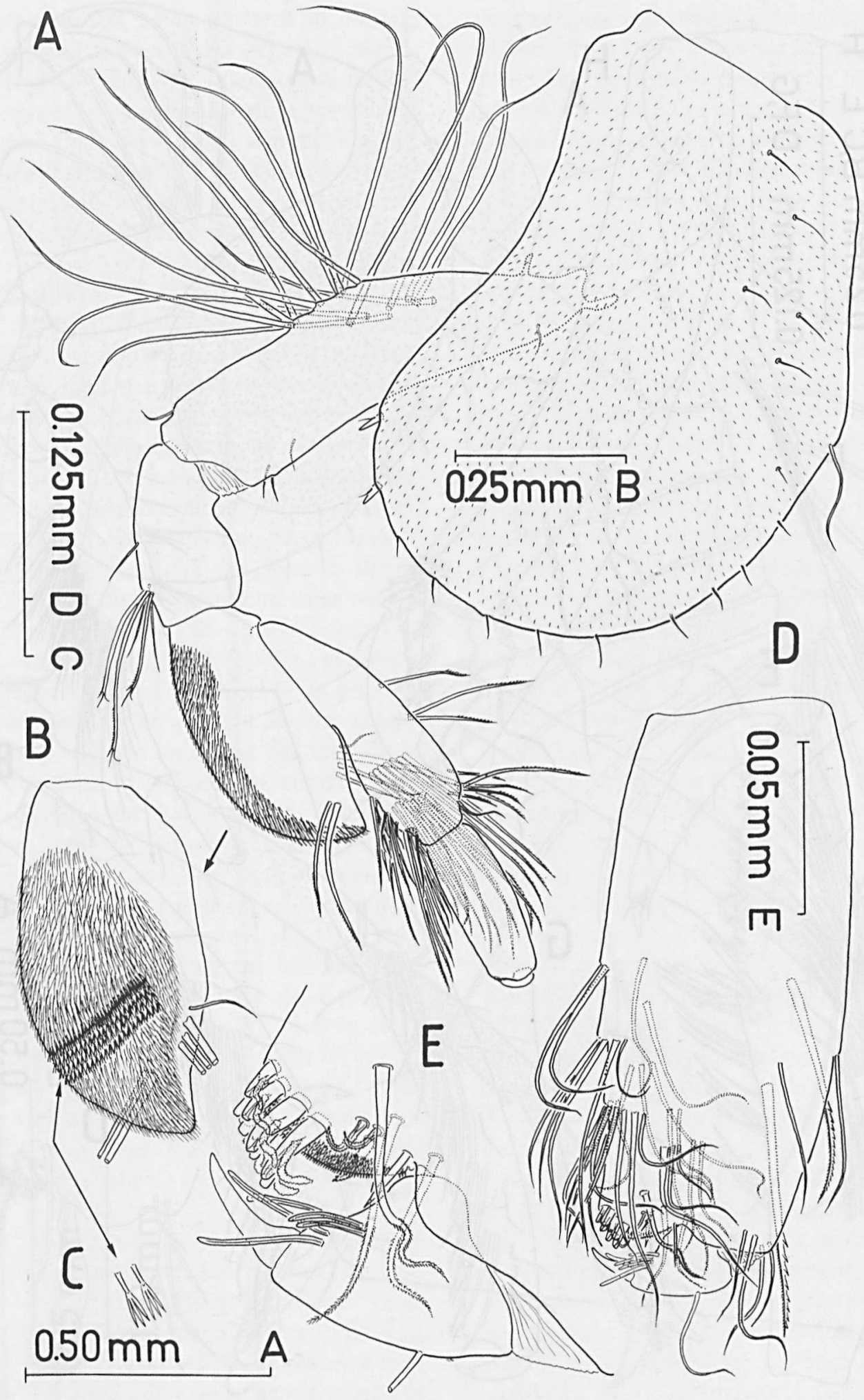

Fig.14. Bahadzia jaraguensis sp. nov., \%: A, gnathopod 1, lateral; B, detail of merus, medial; C, detail of tricuspidate spinules of merus; D, palm, lateral; E, distal part of palm, lateral. 


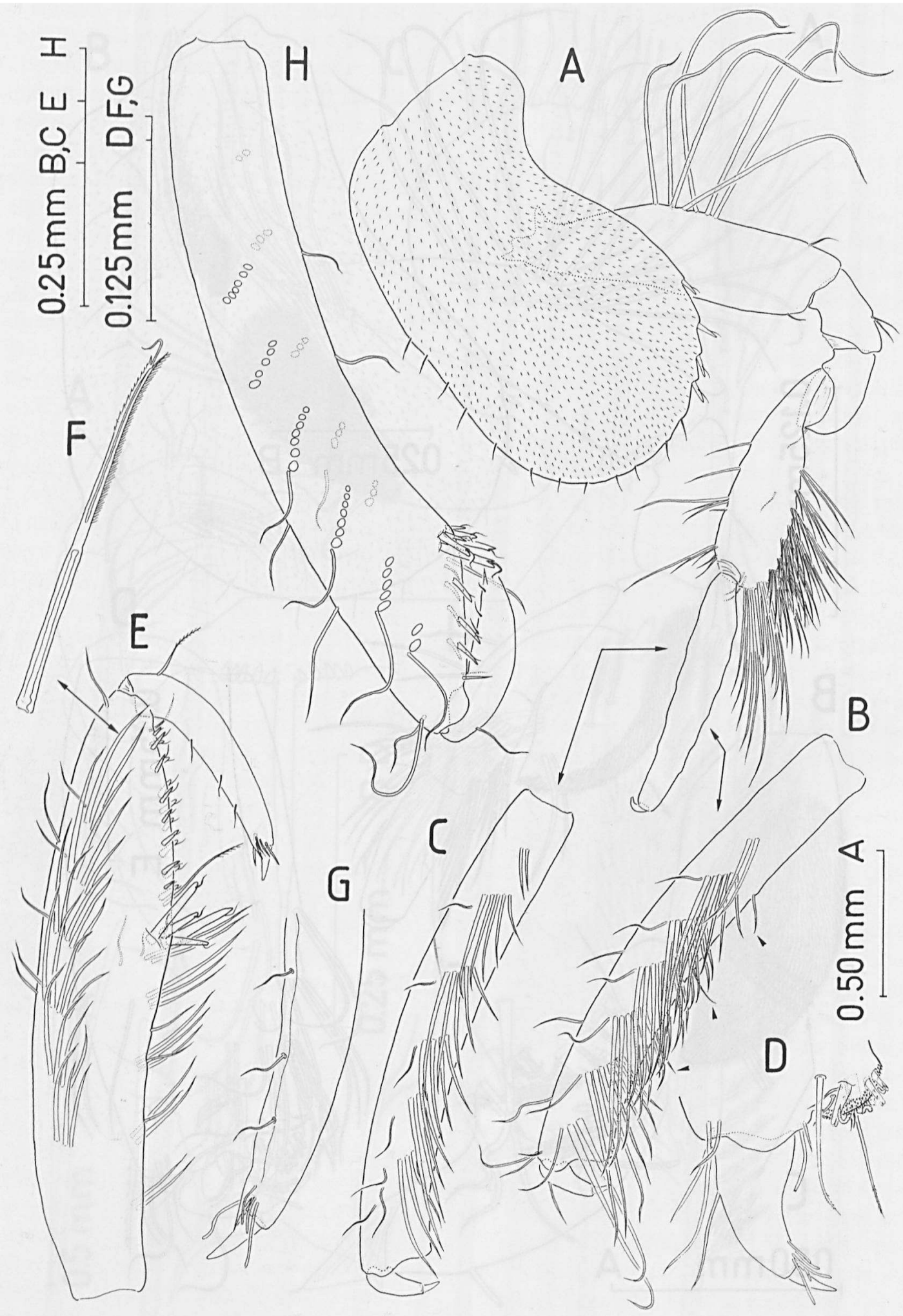

Fig. 15. Bahadzia jaraguensis sp. nov., ९: A, gnathopod 2, lateral (oostegite and coxal gill omitted); B, detail of palm, lateral (arrowheads pointing to setae implanted on posterior margin of article); C, same, medial; D, detail of palm region, lateral; E, gnathopod 2 palm of male of $9.76 \mathrm{~mm}$, lateral; F, detail of one of setae of propodus; $\mathrm{G}$, detail of male dactylus-unguis; $\mathrm{H}$, gnathopod 2 palm of male of $11.06 \mathrm{~mm}$, lateral (transverse rows of setae at each side of article omitted).

Downloaded from Brill.com04/26/2023 12:49:27AM 


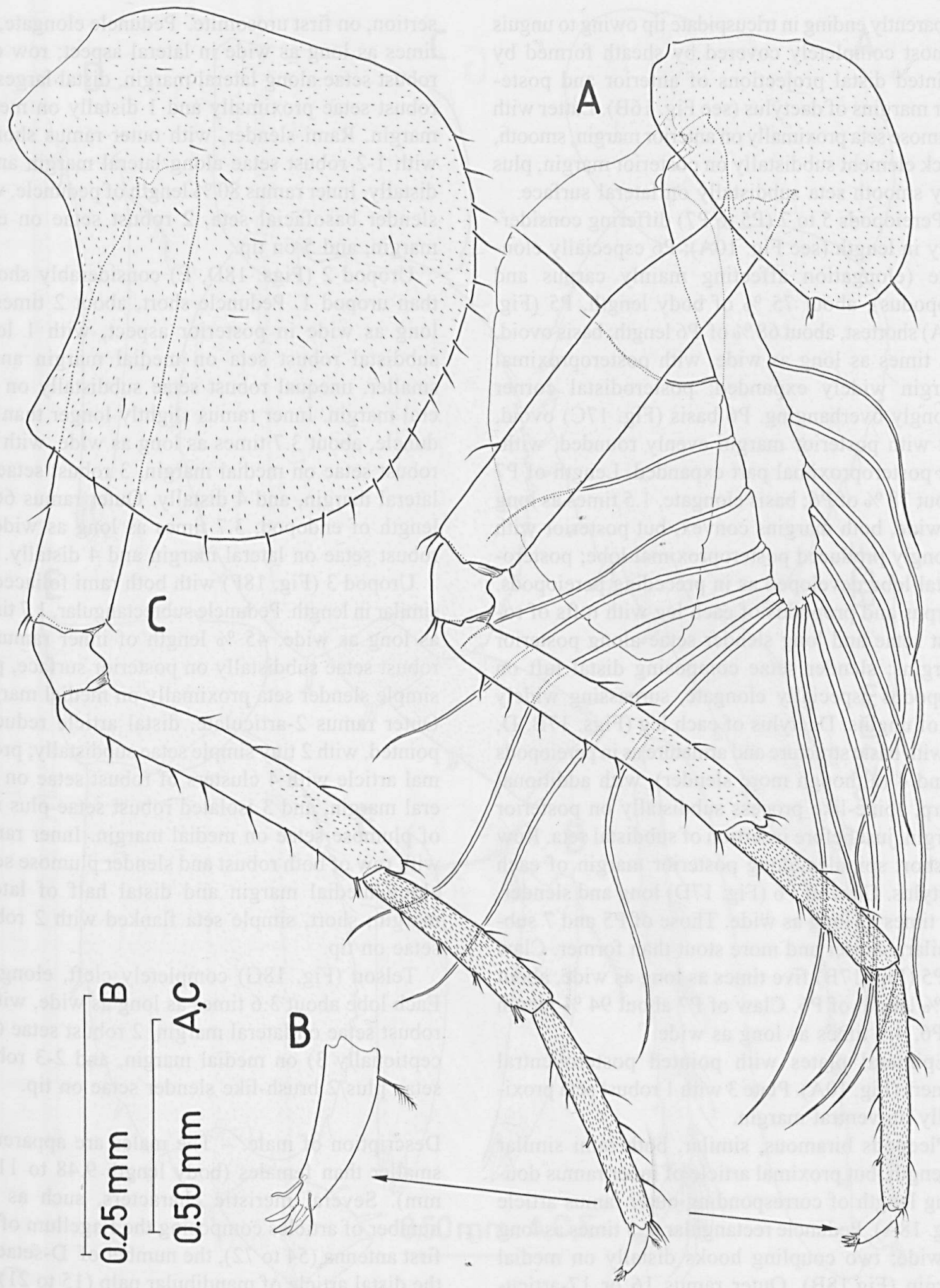

Fig. 16. Bahadzia jaraguensis sp. nov., १: A, pereiopod 3 with oostegite and coxal gill attached; B, dactylus-unguis; C, pereiopod 4 (oostegite and coxal gill omitted). 
apparently ending in tricuspidate tip owing to unguis almost completely covered by sheath formed by pointed distal projections of anterior and posterior margins of dactylus (see Fig. 16B). Latter with plumose seta proximally on anterior margin, smooth, thick element subdistally on posterior margin, plus tiny smooth seta subdistally on lateral surface.

Pereiopods 5 to 7 (P5 to P7) differing considerably in length (see Fig. 10A); P6 especially elongate (elongation affecting mainly carpus and propodus), about $75 \%$ of body length. P5 (Fig. 17A) shortest, about $68 \%$ of P6 length; basis ovoid, 1.2 times as long as wide, with posteroproximal margin widely expanded; posterodistal corner strongly overhanging. P6 basis (Fig. 17C) ovoid, but with posterior margin evenly rounded, without posteroproximal part expanded. Length of P7 about $78 \%$ of P6; basis elongate, 1.5 times as long as wide, both margins convex, but posterior with strongly produced posteroproximal lobe; posterodistal lobe developed as in preceding pereiopods. Carpus and propodus of each leg with tufts of robust setae and long slender setae along posterior margins; slender setae composing distal tuft on propodus especially elongate, surpassing widely tip of unguis. Dactylus of each leg (Figs. 17B, D, F) with basic structure and armature as in pereiopods 3 and 4 (although more slender), with additional sharp, spine-like process subdistally on posterior margin, just before insertion of subdistal seta. Row of short spinules along posterior margin of each dactylus. Claw of P6 (Fig. 17D) long and slender, 7.7 times as long as wide. Those of P5 and 7 subsimilar, shorter and more stout than former. Claw of P5 (Fig. 17B) five times as long as wide, about $81 \%$ length of P6. Claw of P7 about $94 \%$ length of P6, 4.9 times as long as wide.

Epimeral plates with pointed posteroventral corners (Fig. 10A). Plate 3 with 1 robust seta proximally on ventral margin.

Pleopods biramous, similar, both rami similar in length, but proximal article of inner ramus doubling length of corresponding outer ramus article (Fig. 18A). Peduncle rectangular, 2.3 times as long as wide; two coupling hooks distally on medial margin (Fig.18B). Outer ramus 16 or 17-articulate, inner ramus 13 or 14-articulate.

Uropod 1 (Fig. 18C) with robust seta near in- sertion, on first urosomite. Peduncle elongate, 4.4 times as long as wide in lateral aspect; row of 5 robust setae along lateral margin, distal largest; 3 robust setae proximally and 1 distally on medial margin. Rami slender, with outer ramus shorter, with 1-2 robust setae along lateral margin and 4 distally. Inner ramus $80 \%$ length of peduncle, with slender basofacial seta, 2 robust setae on each margin, and 5 on tip.

Uropod 2 (Figs. 18D, E) considerably shorter than uropod 1. Peduncle short, about 2 times as long as wide in posterior aspect, with 1 long, subdistal robust seta on medial margin and 2 smaller, unequal robust setae subdistally on lateral margin. Inner ramus slightly longer than peduncle, about 3.7 times as long as wide, with 3-4 robust setae on medial margin, 3 robust setae on lateral margin, and 4 distally. Outer ramus $66 \%$ length of endopod, 3.7 times as long as wide; 2 robust setae on lateral margin and 4 distally.

Uropod 3 (Fig. 18F) with both rami foliaceous, similar in length. Peduncle subrectangular, 1.7 times as long as wide, $45 \%$ length of inner ramus; 8 robust setae subdistally on posterior surface, plus simple slender seta proximally on medial margin. Outer ramus 2-articulate, distal article reduced, pointed, with 2 tiny simple setae subdistally; proximal article with 4 clusters of robust setae on lateral margin, and 3 isolated robust setae plus row of plumose setae on medial margin. Inner ramus with row of both robust and slender plumose setae along medial margin and distal half of lateral margin; short, simple seta flanked with 2 robust setae on tip.

Telson (Fig. 18G) completely cleft, elongate. Each lobe about 3.6 times as long as wide, with 4 robust setae on lateral margin, 2 robust setae (exceptionally 3 ) on medial margin, and 2-3 robust setae plus 2 brush-like slender setae on tip.

Description of male. - The males are apparently smaller than females (body length 9.48 to 11.06 $\mathrm{mm}$ ). Several meristic characters, such as the number of articles composing the flagellum of the first antenna ( 54 to 72), the number of D-setae on the distal article of mandibular palp (15 to 21), or the number of articles composing each ramus of the pleopods (13 to 16-articulate exopods; 10 to 


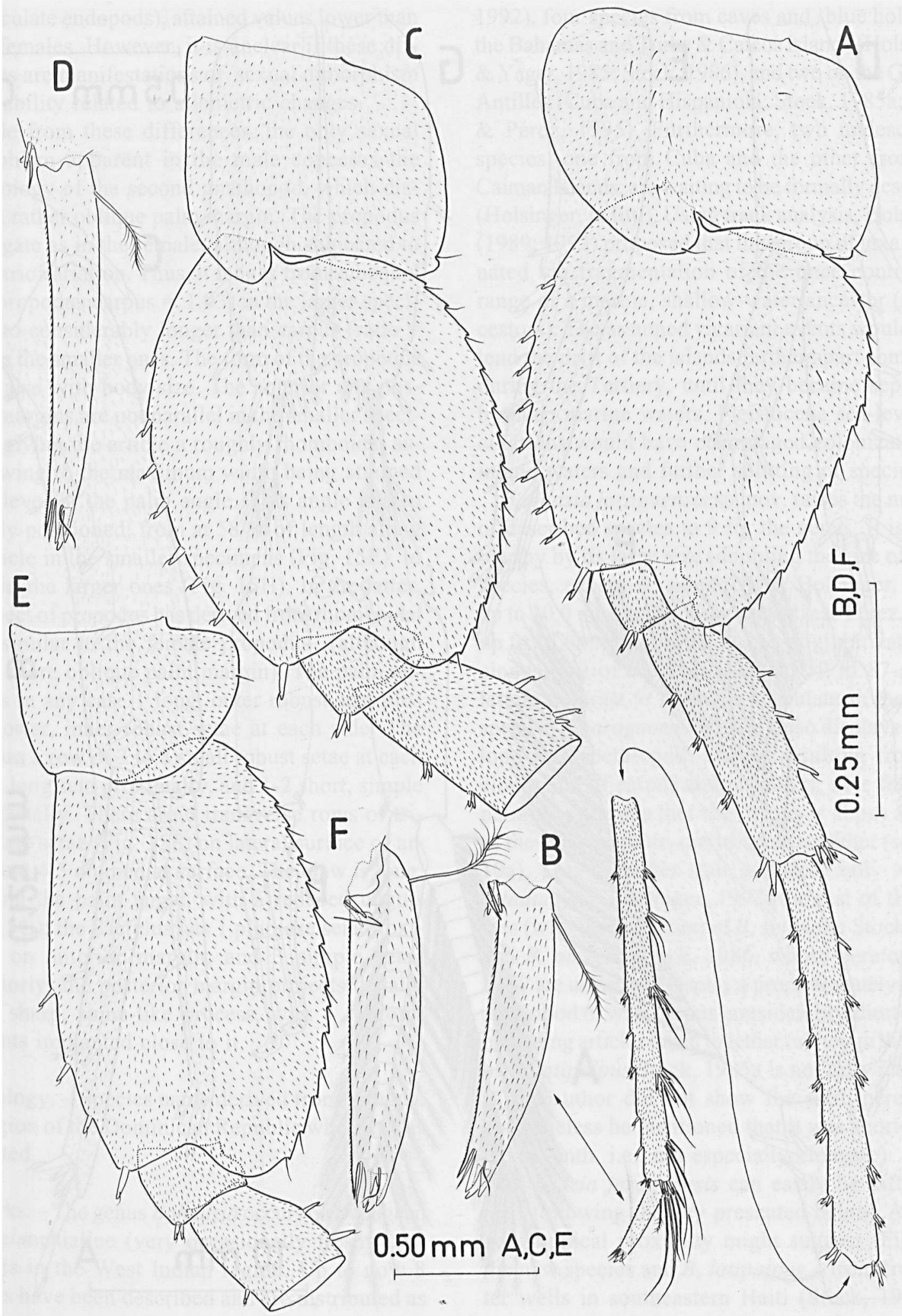

Fig. 17. Bahadzia jaraguensis sp. nov., $९$ : A, pereiopod 5 (oostegite and coxal gill omitted); B, dactylus-unguis; C, proximal articles of pereiopod 6; D, dactylus-unguis; E, proximal articles of pereiopod 7; F, dactylus-unguis. 


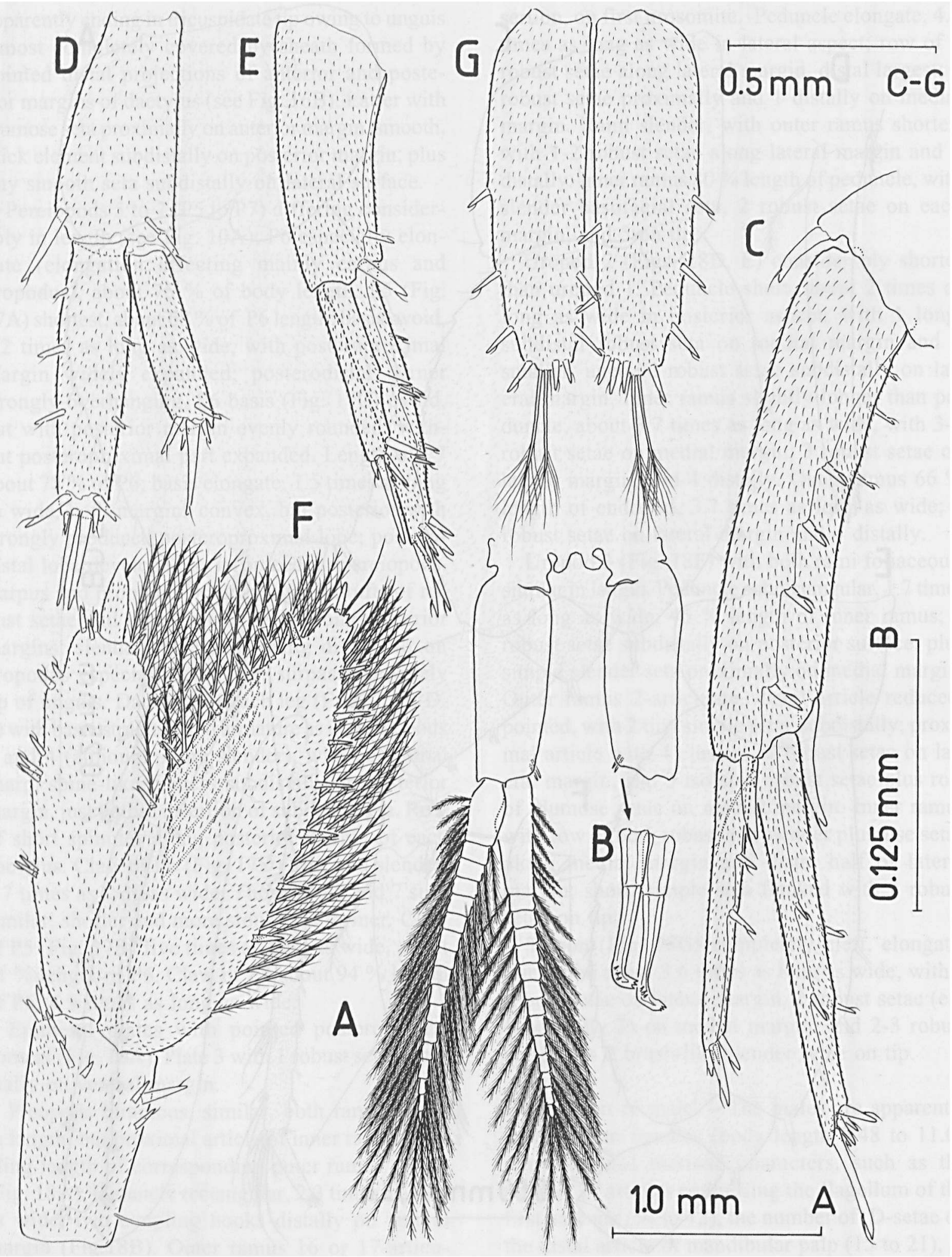

Fig. 18. Bahadzia jaraguensis sp. nov., \& : A, pleopod 1, anterior; B, detail of coupling hooks; C, uropod 1, lateral; D, right uropod 2, posterior; E, left uropod 2, lateral; $\mathrm{F}$, uropod 3, posterior; $\mathrm{G}$, telson, posterior. 
13-articulate endopods), attained values lower than in the females. However, it is unclear if these differences are manifestations of sexual dimorphism or variability related to'allometric changes.

Aside from these differences, the only sexual dimorphism apparent in the male concerns the morphology of the second gnathopod, which displays a rather oblique palm margin. The propodus is elongate as in the female, although subjected to allometric variation. Thus, it ranges from subequal (ratio propodus:carpus $=1.03$ ) in the larger specimens, to considerably longer than carpus (ratio $=$ 1.27) in the smaller ones. The form of the propodus varies also with body size. The anterior and posterior margins are not parallel in the smaller specimens, giving the article a roughly rhomboidal aspect owing to the maximum width being attained at the level of the palm angle. This angle is also variably positioned, from at $58 \%$ of length along the article in the smaller specimens (Fig. 15E) to $78 \%$ in the larger ones (Fig. 15H). In the latter, the aspect of propodus has derived from rhomboidal to be similar to the female propodus (although with a more oblique palm margin). The palm angle has in any case 1 long, outer robust seta plus 1-2 shorter, inner robust setae at each side. The palm has a row of 3 to 8 small robust setae at each side, 1 long seta proximally, and 1-2 short, simple setae distally. There are 6 transverse rows" of tricuspidate setae (Fig. 15F) on lateral surface of article, and 4-5 on medial surface. The claw is long, attaining the palm angle, with a reduced unguis (Fig. 15G); the dactylus has 1 plumose seta proximally on anterior margin, and 3 simple setae posteriorly; the posterior margin projects distally into a sharp, spine-like process, with 4 setiform elements implanted close to it.

Etymology. - Species name derived from Jaragua, the region of the Dominican Republic where it was collected.

Remarks. - The genus Bahadzia occurs on hypogean marine/anchialine (very occasionally freshwater) habitats in the West Indian region. Up to now 8 species have been described and are distributed as follows: two on the Yucatán peninsula of México and the neighboring island of Cozumel (Holsinger,
1992), four species from caves and 'blue holes' in the Bahamas and Turks \& Caicos islands (Holsinger \& Yager, 1985; Stock, 1986), and two on the Greater Antilles (Cuba and Hispaniola; Stock, 1985a; Ortíz \& Pérez, 1995). Furthermore, two undescribed species, one from Cuba and the other from the Caiman Islands, are waiting to be formally described (Holsinger, in litt.). Using track analysis, Holsinger $(1989 ; 1992)$ proposed that this group of taxa originated via fragmentation of the once contiguous range of a marine, shallow-water ancestor (or ancestors). The assumed vicariant events would contend the drift of the islands farther apart sometime during the Tertiary, until they became separated by deep marine waters. Pleistocene sea-level oscillations would have encouraged colonization of inland waters and further splitting of species.

Bahadzia jaraguensis sp. nov. raises the number of described species to 9 for the genus. It is noteworthy by its large size (doubling the size of other species, except $B$. setodactylus Holsinger, 1992, up to $10.0 \mathrm{~mm}$, and B. yagerae Ortíz \& Pérez, 1995, up to $15.0 \mathrm{~mm}$ ) and also by the troglobitization (= elongation) of the first antenna, 59 to 87-articulate in contrast to up to 38-articulate in the other species. $B$. jaraguensis sp. nov, also displays a very long sixth pereiopod, mainly resulting from the elongation of carpus and propodus; note for comparative purposes that the carpus is about as long as the basis-ischium-merus taken together (see Fig. 10a). This character state is shared only with $B$. setodactylus Holsinger, 1992; the rest of the species (with the exception of $B$. setimana Stock, 1986 and B. obliqua Stock, 1986, whose pereiopods 6 and 7 are unknown) display a proportionately shorter pereiopod 6, with carpus considerably shorter than preceding articles taken together (although the status of $B$. latipalpus Stock, 1985a is not fully resolved, as the author did not show the sixth pereiopod; nevertheless he mentioned that it was shorter than the seventh, i.e., not especially elongate).

Bahadzia jaraguensis can easily be differentiated following the key presented below. As their geographical proximity might suggest (Fig. 19), the new species and $B$. latipalpus - from freshwater wells in southeastern Haiti (Stock, 1985a) seem to be closely related. Their close relationship is strongly indicated by the common posses- 

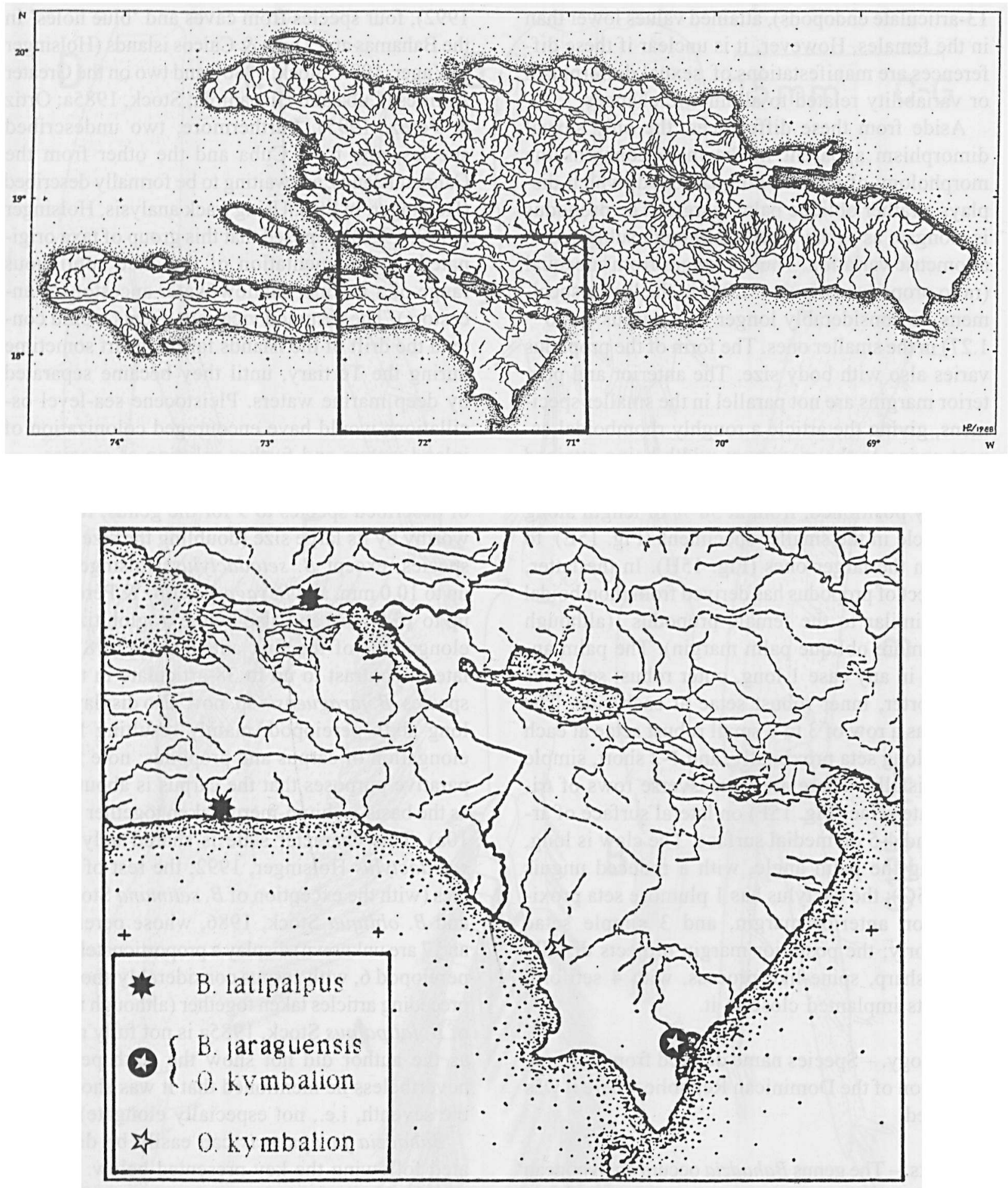

Fig. 19. Distribution of Ottenwalderia kymbalion gen. et sp. nov. and Hispaniolan Bahadzia species (distribution of B. latipalpus after Stock, 1985a: fig. 5). 
sion of a subdistal spiniform process on the dactylus of pereiopods 5 to 7 , a derived character not expressed in the rest of species. The posterodistally produced merus of gnathopod 1 in both taxa is also noteworthy. Nevertheless they can be distinguished for the larger (more than double) body size of $B$. jaraguensis (maximum size recorded for $B$. latipalpus - a female with setose oostegites only $5.0 \mathrm{~mm}$ ), its longer first antenna (59 to 87articulate in comparison to 29-articulate in $B$. latipalpus), the putative absence of inner lobes on the lower lip of B. latipalpus, the very different number of $D$-setae on the third article of mandibular palp (15-24 in $B \times$ jaraguensis, about 6 in $B$. latipalpus), the regressed condition of the coxal gills of B. latipalpus (reduced and unstalked), the relative lengths of pereiopods 6 and 7 (6th considerably longer than 7th in $B$. jaraguensis, whereas slightly shorter than seventh in $B$. latipalpus) and, if not altered by allometric growth, the relative length of carpus and propodus of the female gnathopod 2 (about equal in B. jaraguensis, propodus longer than carpus in $B$. latipalpus).

The locomotory behaviour of $B$. jaraguensis could be observed in natural conditions. In 'Cueva de los Bolos' the animals - forming a dense population - were preponderantly concentrated on the rather fluid, muddy bottom of the lake. There, they walked with pereiopods extended radially like an umbrella. Only rarely they were observed swimming, always with the ventral body side directed to the bottom.

\section{Key to the species of Bahadzia}

1 Coxal plate 3 about same size as preceding plates. Outer plate of first maxilla with many (about 29) pectinate spines. Eye vestigial B. yagerae Ortíz \& Pérez, 1995 (Cuba)

- Coxal plate 3 reduced. Outer plate of first maxilla with 810 pectinate robust setae. Blind

2

2 Merus of gnathopod 1 strongly produced distally into lobe 3

- Merus of gnathopod 1 not produced distally .................. 5

3 Dactylus of pereiopods 5-7 with spine-like process subdistally on posterior margin. No A-seta on third article of mandibular palp
- Dactylus of pereiopods 5-7 normal, without spine-like process. Mandibular palp article 3 bearing A-seta

(Yucatán Península \& Cozumel Is.)

B. bozanici Holsinger, 1992

4 First antenna long (59 to 87-articulate). Pereiopod 6 considerably longer than 7th .......... B. jaraguensis sp. nov. (Dominican Rep., Hispaniola)

- First antenna normal (about 29-articulate). Pereiopod 6 slightly shorter than 7th ......... B. latipalpus Stock, 1985 (Haiti, Hispaniola)

5 Palm of gnathopod 2 strongly oblique. No A-seta on third article of mandibular palp ......... B. obliqua stock, 1986 (Cat Is., Banamas)

- Palm of gnathopod 2 not strongly oblique. A-seta present on third article of mandibular palp ............................ 6

6 Peduncle of uropod 2 with comb row of robust setae distally

- Distal robust setae on peduncle of uropod 2 not forming comb row

7 Dactylus of pereiopod 6 elongate and very setose ...........

(Cozumel Is.)

B. setodactylus Holsinger, 1992

- Dactylus of pereiopod 6 normal, not elongate nor setose B. williamsi Holsinger, 1985

(Grand Bahama \& Great Abaco Is., Bahamas)

8 Distal end of peduncle of uropod 2 with 5 robust setae. Palm angle of gnathopod 2 lacking large robust setae ... $B \times$ stocki Holsinger, 1985

(Providenciales, Turks \& Caicos Is.)

Distal end of peduncle of uropod 2 with 2 robust setae. Palm angle of gnathopod 2 with 4 large robust setae ....

(South Andros Is., Bahamas) B. setimana Stock, 1986

\section{Acknowledgements}

Thanks by the first author are extended to Miquel Trias, Joan R. Bosch, Josep A. Alcover, Bartomeu Segui, Jaume Damians 'Menda' and Guillem Pons for aìd during the cave surveys. José A. Ottenwalder (PNUD, Santo Domingo), Carlos Cano ("Green Caribe', Santo Domingo) and members of 'Grupo Jaragua' (Oviedo) facilitated the fieldwork in many ways. Drs. J. K. Lowry and J. H. Holsinger provided very useful comments on the manuscript. The fieldwork carried out by the second author was financed by a grant received from the Foundation of Fundamental Biological Research (BION), which is subsidized by the Netherlands Organization of Scientific Research (NWO), and acknowledgements from him are also due to the Museo Nacional de Historia Natural, Santo Domingo, for providing laboratory facilities.

Contribution to ICEX-472/95RD (Programa de Cooperación Científica con Iberoamérica, MEC) and Proyecto GEF República Dominicana (PNUD / ONAPLAN). 


\section{References}

Barnard JL. 1964. Deep-sea Amphipoda (Crustacea) collected by $R / V$ Vema in the eastern Pacific Ocean and the Caribbean and Mediterranean Seas. Bull. Amer. Mus. Nat. Hist. 127: $1-46$.

Barnard JL, Karaman GS. 1987. Revisions in classification of gammaridean Amphipoda (Crustacea), Part 3. Proc. biol. Soc. Wash, 100: 856-875.

Barnard JL, Karaman GS. 1991. The families and genera of marine gammaridean Amphîpoda (except marine gammaroíds). Part 2. Rec. Aust. Mus, Suppl. 13 (2): 419-866.

Clark J, Barnard JL. 1985. Lucayarina catacumba, new genus, new species, a Bahamian sea-cave amphipod (Crustacea, Amphipoda, Lysianassidae), Proc. biol. Soc. Wash. 98: 243-254.

Ginés A, Ginés J. 1992. Les Coves del Drac (Manacor, Mallorca). Apuntes históricos y espeleogenéticos. Endins 17/ 18: 5-20.

Holsinger JR. 1989. Preliminary zoogeographic analysis of five groups of crustaceans from anchialine caves in the West Indian region. Proc. I0th int. Congr. Speleol. 1: 25-26.

Holsinger JR. 1992. Two new species of the subterranean Amphipod genus Bahadzia (Hadzilidae) from the Yucatan Peninsula region of southern Mexico, with an analysis of phylogeny and biogeography of the genus. Stygologia 7: $85-$ 105.

Holsinger JR, Yager J. 1985. A new genus and two new species of subterranean amphipod crustaceans (Hadziidae) from the Bahamas and Turks and Caicos islands. Bijdr. Dierk. 55: 283-294.

León RO de. 1989. Geología de la Sierra de Baoruco. Santo Domingo: Museo Nacional de Historia Natural.

Lincoln RJ. 1979. British Marine Amphipoda: Gammaridea. London: British Museum (Natural History).

Lowry JK, Stoddart HE. 1997. Amphipoda Crustacea IV. Families Aristîidae, Cyphocarididae, Endevouridae, Lysianassidae, Scopelocheiridae, Uristidae. Mem. Hourglass Cruises 10(1): 1-148.

Notenboom J. 1991. Marine regressions and the evolution of groundwater dwelling amphipods (Crustacea). J. Biogeogr. 18: 437-454,

Ortíz MR, Pérez A. 1995. Una nueva especie de anfipodo cavernicola hadzioideo (Amphipoda, Gammaridea) de Cuba. Graellsia 51: 165-168.

Sars GO. 1896. Crustacea Caspia. Contributions to the knowledge of the carcinological fauna of the Caspian Sea. Amphi- poda. Supplement. Bull. Acad. Imp. Sc. de St.-Pétersbourg 4: 421-490, 12 pls.

Stephensen K. 1933. Fresh- and brackish-water Amphipoda from Bonaire, Curaçao and Aruba. Zool. Jahrb. (Syst.) 64: 415-436.

Stock JH. 1974. The systematics of certain Ponto-Caspian Gammaridae (Crustacea, Amphipoda). Mitt. hamb. zool. Mus. Inst. 70: 75-95.

Stock JH. 1977. The taxonomy and zoogeography of the hadziid Amphipoda, with emphasis on the West Indian taxa. Stud. Fauna Curacao 55: 1-130.

Stock JH. 1980. Regression model evolution as exemplified by the genus Pseudoniphargus. Bijdr. Dierk. 50: 105-144,

Stock JH. 1985a. Stygobiont amphipod crustaceans of the Hadzioid group from Haiti. Bijdr. Dierk. 55: 331-426.

Stock JH. 1985b. Bogidiellidae (Amphipoda) from Haiti and some general rules on the occurrence of Crustacea Malacostraca in inland groundwaters of the West Indies. Stygologia 1. 208-223.

Stock JH. 1986. Two new amphipod crustaceans of the genus Bahadzia from "blue holes" in the Bahamas and some remarks on the origin of the insular stygofaunas of the Atlantic. $J$ nat. Hist. 20: 921-933.

Stock JH, Iliffe TM. 1990. Amphipod crustaceans from anchihaline cave waters of the Galápagos Islands. Zool. J. Linn. Soc. 98: 141-160.

Stock JH, Iliffe TM, Williams D. 1986. The concept "anchialine' reconsidered. Stygologia 2: 90-92.

Trias M, Ottenwalder JA, Jaume D, Alcover JA. 1997. Una campaña en la Repúblíca Dominicana. Resultados preliminares, Endins 21: 63-74.

Wagner HP. 1990a. The stygobiont isopods of the genus Cyathura in the Dominican Republic (Crustacea; Isopoda; Anthuridae), Bull. zool. Mus., Amsterdam 12(10): 145-158.

Wagner HP. 1990b. Jehaia stocki n,g., n. sp., a new interstitial janiroid isopod from the Dominican Republic, Hispaniola (Crustacea; Isopoda; Janiroidea). Beaufortia 41(26): 187193.

Wagner HP. 1992. Stygiomysis aemete n. sp., a new subterranean mysid (Crustacea, Mysidacea, Stygiomysidae) from the Dominican Republic, Hispaniola. Bijdr. Dierk. 62(2): 71-79.

Wagner HP. 1994. A monographic review of the Thermosbaenacea (Crustacea: Peracarida). A study on their morphology, taxonomy, phylogeny and biogeography. Zool. Verh. 291: 1338.

Received: 25 September 1997 